\title{
Structure Based Design of Novel 6,5 Heterobicylic Mitogen-Activated Protein Kinase Kinase (MEK) Inhibitors Leading to The Discovery of Imidazo [1,5-a] Pyrazine G-479
}

Kirk D. Robarge ${ }^{\mathrm{a}^{*}}$, Wendy Lee ${ }^{\mathrm{a}}$, Charles Eigenbrot ${ }^{\mathrm{b}}$, Mark Ultsch $^{\mathrm{b}}$, Christian Wiesmann $^{\mathrm{b}}$, Robert Heald ${ }^{\mathrm{c}}$, Steve Price ${ }^{\mathrm{c}}$, Joanne Hewitt ${ }^{c}$, Philip Jackson ${ }^{c}$, Pascal Savy ${ }^{c}$, Brenda Burton ${ }^{c}$, Edna F. Choo ${ }^{d}$, Jodie Pang ${ }^{d}$, Jason Boggs ${ }^{d}$, April Yang $^{d}$, Xioaye Yang ${ }^{d}$, Matthew Baumgardner ${ }^{d}$

${ }^{a}$ Discovery Chemistry, Genentech Inc., 1 DNA Way, South San Francisco California, USA.

${ }^{b}$ Structural Biology, Genentech Inc., 1 DNA Way, South San Francisco California, USA.

${ }^{c}$ Argenta, Discovery Services Charles River 8-9 Spire Greene Centre, Harlow, Essex, CM 19 5TR, United Kingdom

${ }^{d}$ Drug Metabolism and Pharmacokinetics, Genentech Inc., 1 DNA Way, South San Francisco California, USA.

*Corresponding author. Tel.: +1-650-225-2320; fax: +1-650-742-4943; e-mail: kir@gene.com

\section{[Insert Graphical Abstract here]}

Abstract: Use of the tools of SBDD including crystallography led to the discovery of novel and potent 6,5 heterobicyclic MEKi's. ${ }^{1 * *}$ The core change from a 5,6 heterobicycle to a 6,5 heterobicycle was driven by the desire for increased structural diversity and aided by the co-crystal structure of G-925. ${ }^{1 * *}$ The key design feature was the shift of the attachment of the five membered heterocyclic ring towards the B ring while maintaining the key hydroxamate and anilino pharamcophoric elements in a remarkably similar position as in G-925. From modelling, changing the connection point of the imidazole heterocycle placed the $\mathrm{H}$-bond accepting nitrogen within a good distance and angle to the Ser212..$^{* *}$ The resulting novel 6,5 benzoisothiazole MEKi G-155 exhibited improved potency versus aza-benzofurans G-925 and G-963 but was a potent inhibitor of cytochrome P450's 2C9 and 2C19. Lowering the $\log D$ by switching to the more polar imidazo [1,5- $a$ ] pyridine core significantly diminished $2 \mathrm{C} 9 / 2 \mathrm{C} 19$ inhibition while retaining potency. The imidazo $[1,5-a]$ pyridine G-868 exhibited increased potency versus the starting point for this work (aza-benzofuran G-925)leading to deprioritization of the azabenzofurans. The 6,5imidazo [1,5- $a$ ] pyridine scaffold was further diversified by incorporating a nitrogen at the 7 position to give the imidazo [1,5- $a$ ] pyrazine scaffold. The introduction of the $C 7$ nitrogen was driven by the desire to improve metabolic stability by blocking metabolism at the $\mathrm{C} 7$ and $\mathrm{C} 8$ positions (particularly the HLM stability). It was found that improving on G-868 (later renamed GDC-0623) required combining C7 nitrogen with a diol hydroxamate to give G-479. G-479 with polarity distributed throughout the molecule was improved over G-868 in many aspects.

\section{Abbreviations}

MAPK/ERK kinase (MEK) signaling cascade- The pathway includes many proteins, including MAPK (mitogenactivated protein kinases, originally called ERK, extracellular signal-regulated kinases), which communicate by adding phosphate groups to a neighboring protein, which acts as an "on" or "off" switch. Also known as the RASRAF-MEK-ERK mitogen-activated protein kinase signaling pathway; KRAS- GTPase KRas also known as V-Ki-ras2 Kirsten rat sarcoma viral oncogene homolog and KRAS, is a protein that in humans is encoded by the KRAS gene; NRAS- The N-ras oncogene is a member of the Ras gene family and an enzyme that in humans is encoded by the NRAS gene. It was named NRAS for its initial identification in human neuroblastoma cells; HRAS- GTPase HRas also known as transforming protein p21 is an enzyme that in humans is encoded by the HRAS gene. Once bound to 
guanosine triphosphate, activates a Raf kinase like c-Raf, the next step in the MAPK/ERK signaling cascade; BRAFBRAF is a human gene that makes a protein called B-Raf. The gene is also referred to as proto-oncogene B-Raf and $v$-Raf murine sarcoma viral oncogene homolog $B$, while the protein is more formally known as serine/threonineprotein kinase B-Raf; RAF- proto-oncogene serine/threonine-protein kinase also known as c-RAF; AKT- AKT is also known as protein kinase $\mathrm{B}(\mathrm{PKB})$, is a serine/threonine-specific protein kinase that plays a key role in multiple cellular processes such as glucose metabolism, apoptosis, cell proliferation, transcription and cell migration; PI3KPhosphatidylinositol-4,5-bisphosphate 3-kinase are a family of enzymes involved in cellular functions such as cell growth, proliferation, differentiation, motility, survival and intracellular trafficking, which in turn are involved in cancer; MEKi's- MAPK/ERK kinase (MEK) signaling cascade inhibitors. A MEK inhibitor is a chemical or drug that inhibits the mitogen-activated protein kinase kinase enzymes MEK1 and/or MEK2. Allosteric MEK inhibitors described herein inhibit both MEK 1 and MEK2; MEK 1,2 inhibitors are synonomous with MEKi's; ATP- Adenosine triphosphate is a nucleoside triphosphate used in cells as a coenzyme; H-bond- Hydrogen bond; BID- twice daily; QD- once daily; CYP-Cytochrome P450; $\operatorname{logD}$ (measured)- Distribution-coefficient is the ratio of concentrations of a compound in a mixture of two immiscible phases at equilibrium. These coefficients are a measure of the difference in solubility of the compound in these two phases. LogD's have a pH dependence. LogD measurements for MEKi's disclosed herein were performed at pH 7.4; clogD- Calculated logD @ pH 7.4; clogP- Calculated partition-coefficient (clogP) is the calculated ratio of concentrations of a compound in a mixture of two immiscible phases at equilibrium. These coefficients are a measure of the difference in solubility of the compound in these two phases. The clogP value reflects the overall lipophilicity of a molecule; IV- delivered directly into the vein; POby mouth; Mic(H/R/M/D/C)-Microsomes H(human)/R (rat)/M (mouse)/D (dog)/C (cyno). Incubation of the MEKi's described herein was conducted with liver microsomes from human(HLM) and pre-clinical species $\operatorname{rat}(\mathrm{RLM})$, mouse(MLM), $\operatorname{dog}(\mathrm{DLM})$, and cyno(CLM) to assess comparative metabolic stability; PEG 400- polyethylene glycol 400 is a low-molecular-weight grade of polyethylene glycol miscible with water and used as vehicle for dosing rats IV and PO; CLp- In vivo total plasma clearance is defined as the volume of blood or plasma cleared of drug in a unit time. It is related to the volume in which the drug is dissolved and the rate at which it is eliminated; T1/2 (hr)- half life of MEK inhibitor when dosed intraveneously; ppb- plasma protein binding; Oral exposure- Area Under the plasma concentration versus time Curve(AUC); \%F- oral bioavailability which is the dose-corrected area under curve (AUC) after oral dosing divided by AUC intravenous; IV/IV -in vitro/ in vivo clearance correlation (CL predicted from rat microsome incubation/ versus $\mathrm{CL}$ observed after intraveneous administration in rat)

\section{Keywords}

Mitogen-Activated Protein Kinase Kinase Inhibitors

MEK inhibitors

RAS signaling pathway

Imidazo[1,5a] Pyrazine

Imidazo[1,5a] Pyridine

Structure Based Drug Design(SBDD)

Oncology

The MAPK/ERK kinase (MEK) signaling cascade is a key regulator of cellular proliferation, differentiation and survival downstream of RAS activation. ${ }^{2}$ Upregulation of this pathway occurs in a large fraction of tumors, frequently owing to oncogenic activating mutations in KRAS, NRAS, HRAS and BRAF. ${ }^{3}$ Constitutive activation of the extracellular regulated kinase (ERK) cascade, through oncogenic forms of RAS and mutations in BRAF, has been observed in lung, colon, pancreas, kidney, and ovary primary human tumor samples. ${ }^{4}$ Whereas BRAF inhibitors have shown remarkable efficacy against melanomas with BRAF (V600E) mutations, these compounds are not effective against KRAS-mutant tumors owing to inhibitor-mediated priming of wild-type RAF signaling. ${ }^{5-7}$ As MEK is 
a common effector downstream of wild-type and mutant RAF, 8,9 MEK inhibitors have the potential to target all tumors dependent on MAPK pathway signaling.

The RAS-RAF-MEK-ERK mitogen-activated protein kinase signaling pathway has emerged as one of the most promising targets for molecularly targeted antitumor agents. Currently, at least twelve MEK inhibitors are at some stage of clinical evaluation for the treatment of cancer (three others have been discontinued) and one has been approved by the FDA for use as a single agent for melanoma (Mekinist ${ }^{\mathrm{TM}}$, aka trametinib or GSK 1120212). Many in the field of targeted therapies believe there is greater potential for MEK inhibitors if they are used in combination with other targeted agents such as $\mathrm{BRAF}^{10}, \mathrm{AKT}^{11}, \mathrm{PI} 3 \mathrm{~K}$ inhibitors ${ }^{12,13}$ and immunotherapies ${ }^{14}$. Combination therapy has been suggested to better inhibit the MAPK/ERK kinase pathway and therefore prolong treatment effect. The results of phase 1 and 2 clinical studies utilizing a selective BRAF inhibitor, Tafinlar $^{\mathrm{TM}}$ (aka dabrafenib), and the selective MEK inhibitor, trametinib, demonstrated the benefit of a combination approach. It was found that dabrafenib and trametinib could be safely combined at $150 \mathrm{mg}$ BID/ $2 \mathrm{mg}$ QD with rare doselimiting side effects. The combination therapy significantly improved progression free survival and patients showed a higher rate of response in comparison to dabrafenib monotherapy. ${ }^{10}$ However, despite the benefit demonstrated by the MEK/BRAF combination, resistance still developed in most patients after an average of 9.4 months. The mechanisms of resistance to combined RAF/MEK inhibition remain poorly understood. ${ }^{15}$

MEK 1,2 inhibitors ${ }^{16}$ bind to an allosteric binding site proximal to the ATP binding site and as a result are exquisitely selective. These compounds form a tertiary complex with the MEK enzyme and ATP and are ATP noncompetitive. ${ }^{17,18}$ The binding site for allosteric MEK inhibitors has been previously described. ${ }^{1 * *}$ There are seven structurally related MEK inhibitors in the clinic that all possess an anilino "B-ring" which occupies a lipophilic pocket formed by Leu118, Ile126, Val127, lle141, Met143, Phe129, Phe209, and Val211 (Fig.1). These MEKi's all incorporate a halogen at the para position which is lipophilic and polarizable and capable of engaging the carbonyl of Val127 in a halogen bond. Additionally these ATP noncompetitive MEKi's all have a polar group capable of engaging the terminal phosphate of ATP and Lys97. This polar group is typically a hydroxamate, but other polar functionalities such as an amide, a reverse sulfonamide, or a sulfonyl urea can be utilized. A third binding feature is an $\mathrm{H}$-bond acceptor to Ser212. It has recently been disclosed that certain MEKi's with superior efficacy against KRAS tumors form a strong $\mathrm{H}$-bond interaction with the Ser212 in MEK that is critical for blocking MEK feedback phosphorylation by wild-type RAF. ${ }^{19}$ The strength of the Ser $212 \mathrm{H}$-bond interaction and position relative to the aniline and hydroxamate is determined by the "A-ring" to which these moieties are attached (Fig.1). It has been proposed that increasing the strength of the Ser212/H-bond acceptor interaction results in greater tolerance in the other pharmacophoric elements. A potent MEK inhibitor requires having all three of these binding interactions in place.

\section{[Insert Figure 1 and Figure 1 caption here]}

In our search for novel MEK inhibitors, we leveraged key information from the X-ray crystal structure of our previously disclosed 5,6 heterobicyclic azabenzofuran G-925 to scaffold hop to a new class of 6,5 heterobicyclic MEKi's ${ }^{1 * *}$ which, like the 5,6 azabenzofuran, engaged the Ser212 in a monodentate interaction. The scaffold hop from the 6,5 to the 5,6 heterobicylic scaffold was driven by two factors: 1 ) increasing the structural diversity and 2) to further our understanding of the influence of the A ring on the placement of the Ser212 $\mathrm{H}$-bond accepting nitrogen and how that impacts potency. Modelling indicated the 6,5 isobenzothiazole G-155 would be tolerated in the MEK binding pocket with the $\mathrm{H}$-bond accepting nitrogen capable of making a good interaction with Ser212. As shown in Figure 2, the 6,5 heterobicyclic isobenzothiazole G-155, while equipotent in the 
biochemical assay showed increased potency versus its azabenzofuran comparator G-963 in both cell proliferation assays. Typically for our potent MEKi's, the biochemical assay was not as useful as the $72 \mathrm{~h}$ cell proliferation assays for differentiation. The cell proliferation (particularly the HCT116 cell proliferation assay) potency was the decision

making potency readout used to differentiate our potent MEKi's and determine their progression.

\section{[Insert Figure 2 and Figure 2 caption here]}

Although isobenzothiazole G-155 was potent, progression was halted due to potent 2C9/2C19 CYP inhibition (Table 1). It was reasoned that the CYP 2C9/2C19 inhibition could be reduced by lowering lipophilicity and $\log \mathrm{D}$. A decision was made to introduce polarity into the core and scaffold hop to 6,5 imidazo [1,5-a] pyridines. In addition to lowering the lipophilicity (reflected in the measured logD @ pH 7.4) versus the isobenzothiazole, the imidazo[1,5- $a$ ] pyridine core increased the structural diversity of the 6,5 heterobicyclic MEKi's and differentiated the pKa's (cpKa's using MOKA1.1.0 for G-155/G-868=1.83/4.78) which can effect the strength of the $\mathrm{H}$-bond interaction with Ser212. Both imidazo $[1,5-a]$ pyridines $\mathbf{G}-868^{20,21}$ and $\mathbf{G}-\mathbf{6 0 6}^{22}$ retained cell proliferation potency and exhibited greatly reduced 2C9(warfarin) /2C19 (mephenytoin) inhibition (Table 1). Imidazo [1,5-a] pyridines G-868 and G-606 did not inhibit cytochrome P450's 3A4 (testosterone/midazolam), 2D6 (dextromethorphan) and 1A2 (phenacetin). With three examples of 6,5 heterobicyclic MEKi's with increased potency versus their direct aza-benzofuran comparator (G-963), the 5,6 aza-benzofuran core was deprioritized.

\section{[Insert Table 1 and Table 1 caption here]}

The potency of the 6,5 heterobicyclic MEKi's indicate the positioning of the pharmacophore elements, including the Ser212 H-bond acceptor nitrogen, are well tolerated in the MEK binding pocket. The polar functionality (A-ring dependent) are positioned optimally as shown by the X-ray co-crystal structures in Figure 3.

\section{[Insert Figure 3 and Figure 3 caption here]}

The imidazopyridine class of MEKi's replaced the benzoisothiazoles with the 5-imidazo [1,5-a] pyridines preferred versus the 8-imidazo [1,5- $a$ ] pyridines. G-868 was chosen as our new lead. G-868 exhibited improved predicted metabolic stability in dog and cyno microsomes, low total CL in vivo, longer IV half life, higher AUC and \%F versus the its direct comparator 8-imidazo[1,5-a] pyridine G-606 (Table2). The G-868/G-606 comparison and conclusion is representative of the bigger data set of 5 -imidazo versus 8 -imidazo [1,5- $a$ ] pyridines. Note that both the 5 and 8 - imidazo [1,5- $a$ ] pyridines inhibit the hERG channel.

\section{[Insert Table 2 and Table 2 caption here]}

For the 5-imidazo [1,5-a] pyridines we observed poor in vitro/in vivo $\mathrm{CL}$ correlation (IV/IV, see Supplemental Material) in rat and G-868 was no exception. Despite efforts to understand the IV/IV disconnect, a satisfactory explanation was elusive and a decision was made to put more weight on in vivo studies in rat. Our qualitative met ID studies indicated G-868 was stable in rat (82\%). Some metabolism occurred on the hydroxamate (10\% acid, $5 \%$ amide, see Supplemental Material; in mouse there is some turnover-NADPH, which appears to be hydrolysis to the acid and accounts for $1.2 \%$ of total). Even though our met ID data did not indicate C 8 as a site of metabolism, 
Metasite $^{\mathrm{TM} 23,24}$ did. Thus, G-879 $\left(\mathrm{HCT} 116 \mathrm{IC}_{50}=0.14 \mu \mathrm{M}\right)$ ), containing a C8-fluorine was synthesized. From a cell proliferation potency standpoint, the $\mathrm{C} 8$ fluorine was not detrimental to potency. However, consistent with the Metasite analysis, C8 fluorine incorporation lowered in vivo CLp, increased half life and oral exposure in rat, consistent with blocking a site of metabolism. Unfortunately CYP2C9 inhibition activity for G-879 increased sevenfold.

\section{[Insert Figure 4 and Figure 4 caption here]}

Encouraged it was possible to reduce total and free drug clearance $(\mathbf{G}-879 \mathrm{ppb}$ rat $=97 \%$, free drug $\mathrm{CL}=55$ $\mathrm{mL} / \mathrm{min} / \mathrm{kg}$ vs. $1320 \mathrm{~mL} / \mathrm{min} / \mathrm{kg}$ for $\mathbf{G - 8 6 8}$, ppb rat = 99\%), increase $\mathrm{T} 1 / 2$ and oral exposure by blocking C8, a second Metasite analysis (Figure 5 ) indicated that incorporation of a nitrogen at C7 would block metabolism at both $\mathrm{C7}$ and $\mathrm{C} 8$ (Figure 5). Incorporation of a nitrogen at C7 of the imidazo [1,5- $a$ ] pyridine core was also anticipated to have additional benefits by lowering the cLogP/cLogD and decreasing the pKa for the imidazo [1,5a] pyrazines. Decreasing lipophilicity along with decreasing basicity would increase the probability of improving the hERG IC 50 $_{50}$ versus G-868. Based on met ID data, the hydroxamate was the major metabolic site of G-868 and one way to modulate clearance would be to make the hydroxamate less prone to hydrolysis. However, it was difficult to predict a priori how the N7 nitrogen and lower lipophilicity would effect the metabolism of the hydroxamate. G-593 was synthesized to determine if an imidazo [1,5- $a]$ pyrazine could further improve on the imidazo $[1,5-a]$ pyridine $\mathbf{G}-868$.

\section{[Insert Figure 5 and Figure 5 caption here]}

As shown in Table 3, the incorporation of a nitrogen at C7 (G-593) lowered the cLogP/cLogD versus G-868. Both MOKA and the ACD software predicted a lower pKa, though the magnitude of decrease is different. The measured pKa's validated the predictions as the pKa for G-593 is two units lower versus G-868. However, despite the lower CLogP/CLogD and decreased pKa, there is no change in the hERG IC 50 . The measured $\operatorname{logD}(@ \mathrm{pH}$ 7.4) shows identical values for G-868 and G-593, a possible reason for lack of improvement in the hERG IC $\mathrm{C}_{50}$. That the overall hydrophobicity, as reflected in $\log \mathrm{D}$ measurements, is identical may reflect "buried" polar surface area in G-593 if the hydroxamate $\mathrm{NH}$ is engaged in an $\mathrm{H}$-bonding interaction with $\mathrm{N7}$. Such an interaction may not be reflected in the $\log \mathrm{D}$. The working hypothesis that came out of this result was that for the imidazo [1,5- $a$ ] pyridine MEKi's (Table 3 ) any improvement in $\mathrm{hERG} \mathrm{IC}_{50}$ is likely to be driven by decreased lipophilicity (i.e. lowering measured $\log \mathrm{D}$ ). The imidazole nitrogen in $\mathbf{G - 8 6 8}$ is not very basic to begin with (pKa 4.30), so lowering its pKa does not impact the hERG IC 50 .

\section{[Insert Table 3 and Table 3 caption here]}

\section{[Insert Figure 6 and Figure 6 caption here]}

Though the anticipated improvement in $\mathrm{hERG} \mathrm{IC}_{50}$ was not realized, further exploration of the imidazo [1,5-a] pyrazines was conducted. As shown in Table 4, the cell proliferation potency lost by the addition of a nitrogen at the 7 position could be regained with a more hydrophobic side chain without increasing the logD (G$\mathbf{5 9 3}$ vs. G-327). G-593 and G-327 exhibited higher total CL and lower exposure than G-868. However, unlike the imidazo [1,5-a] pyridine class of MEKi's, the in vivo clearance was in line with that predicted from in vitro RLM stabilities. The lower total clearance exhibited by G-868 may be due in part to its high plasma protein binding . The most pronounced effect of the $N 7$ modification was decreasing plasma protein binding. Plasma protein binding 
was decreased across species (3-9\%, 7\% lower in rat ). The nitrogen in G-593 increased metabolic stability and so lowered the unbound clearance (G-593 600 mL/min/kg versus G-868 1320 mL/min/kg; ppb (rat) G-868= 99\%, G$593=92 \%$ ). Permeability in the A-B direction increased for G-593 with reduced efflux ( $B-A / A-B=0.7$ vs. 2.60 for GDC-868).The improved permeability may be a result of an effective decrease in polar surface area due to the hydroxamate $\mathrm{NH}$ engaging in an $\mathrm{H}$-bonding interaction with $\mathrm{N7}$. While such an interaction may not be reflected in the $\log D$ it could result in improved permeability. Lowering of the plasma protein binding resulting in a lowering of the free drug clearance and improved permeability demonstrated C7 nitrogen modification could influence drug like properties in a positive way.

Encouraged by the improved permeability and the decreased free drug clearance we revisited our working hypothesis that we could improve the hERG $I C_{50}$ by lowering logD. It was reasoned that adding a more polar hydroxamate side chain would lower the logD. Additionally, spreading polarity throughout the molecule is one strategy that has been utilized to improve hERG by destabilizing the interaction with the lipophilic cavity of the hERG channel. ${ }^{25}$ Our microsome stability calculations indicated improvement in metabolic stability across species with the additional polarity. Incorporation of the diol hydroxamate sidechain in G-479 lowered the measured LogD and an improvement in the hERG IC 50 was realized (Table 4). As predicted by in vitro RLM's (the pyrazines exhibited an excellent IV/IV correlation for rat), G-479 exhibited improved metabolic stability in rat, lower plasma protein binding across species, improved MDCK permeability (less efflux), lower free drug CL ( $92 \mathrm{~mL} / \mathrm{min} / \mathrm{kg}$ vs $1300 \mathrm{~mL} / \mathrm{min} / \mathrm{kg}$ for G-868), and increased LLE (Supplemental Material) compared with G-868. The in vivo total CLp in rat was equivalent to G-868, the exposure and \%F much improved versus G-593 and G-327. The oral exposure of G-479 was only two fold lower than that of the lead imidazo [1,5-a] pyridine G-868. Since the secondary hydroxyl of the diol hydroxamate had no effect on cell proliferation potency (G-593 120 nM vs. G-479 $107 \mathrm{nM}$ ), the potency loss suffered by G-479 can be rationalized by a weaker interaction with the Ser212 nitrogen due to the less basic $\mathrm{H}$-bond accepting nitrogen.

\section{[Insert Table 4 and Table 4 caption here]}

The imidazo[1,5-a]pyrazines were synthesized by the following 10 step synthetic route.

\section{[Insert Scheme1 and Scheme 1 caption here]}

Some interesting features of the chemistry included the following:

(a) The reaction did not work at all using LDA obtained from commercial sources. It was necessary to freshly prepare the LDA to obtain 2. (b) In the conversion of $\mathbf{2}$ to $\mathbf{3}$, if LDA was used as the base it was prepared fresh since that was considered best practice. However, commercial LHDMS ( Aldrich) could be used as the base with comparable yields.

(e) In the synthesis of G-868 the reduction of the nitrile to the benzyl amine was accomplished in good yield by a $\mathrm{CoCl}_{2} / \mathrm{NaBH}_{4} / \mathrm{MeOH}$ reduction. ${ }^{20,21}$ Applying the same procedure to $\mathbf{5}$ gave no product. In the case of pyrazine $\mathbf{5}$, the major product isolated from the $\mathrm{CoCl}_{2} / \mathrm{NaBH}_{4}$ mediated reduction of 5 was the 2-F 4-TMS aniline. This result necessitated the screening of several reduction conditions to find one that cleanly transformed $\mathbf{5}$ into $\mathbf{6}$. It was 
found that it was absolutely necessary to run the hydrogenation reaction in glacial acetic acid to achieve a high yield of crude 6 (presumably the acetate salt) which was of suitable purity to be taken on directly. This result also indicated the imidazo $[1,5-a]$ pyrazine core is stable under acidic but not basic reaction conditions

(e)-(h) Crude material was carried through steps (e)-(h) and purification performed on intermediate 9

(i) It was necessary to hydrolyze the ester using tin mediated hydrolysis conditions at $85^{\circ} \mathrm{C}^{35}$ as the more standard hydrolysis conditions of $\mathrm{LiOH} / \mathrm{THF} / \mathrm{MeOH} / \mathrm{H}_{2} \mathrm{O}$ resulted in decarboxylation. This result was consistent the previous observation that the imidazo [1,5- $a$ ] pyrazine core was stable under acidic reaction conditions ( even with heating to $85^{\circ} \mathrm{C}$ !!) but not basic reaction conditions.

(j) Changing the base from DIPEA to 4-methylmorpholine improved the yield of the coupling reaction 4.5 fold ( $11 \%$ to $50 \%)$

In planning for success and scalability, there was precedent in the MEK patent literature for hydroxamate formation directly from the ester (74\% yield on a $200 \mathrm{~g}$ scale). ${ }^{39}$ While the imidazo [1,5a] pyrazines were prepared on 50-200 mg scale with the final step being an EDCI/HOBT coupling, we did also explore hydroxamate formation directly from the methyl ester( Fig. 10). When preparing the hydroxamate from the methyl ester, it was critical to use three equivalents of the LHMDS base. Two representative examples are shown below.

\section{[Insert Scheme 2 and Scheme 2 caption here]}

A plot of the biochemical potency versus LogD and cLog P (overall hydrophobicity) can be found in the Supplemental Material. Both the LLE vs. measured LogD and calculated CLogP plots show a progression of the 6,5 heterobicyclic MEKi's towards greater LLE. Imidazo [1,5- $a$ ] pyrazine G-479 gained 1.5 units in LLE and is the most ligand efficient 6,5 heterobicycle described in this manuscript.

Leveraging X-ray crystal structure data for G-925 gave rise to novel 6,5-heterobicyclic cores. The starting point for this work was the novel 6,5 heterobicyclic isobenzothiazole MEKi which interacted with Ser212 in a monodentate fashion as did G-925 but exhibited increased cell proliferation potency. ${ }^{1 * *}$ Unfortunately isobenzothiazole G-155 was a potent 2C9/2C19 inhibitor which prompted a core change to a more polar 6,5 heterobicyclic core. The imidazo [1,5-a] pyridine core with lower lipophilicity eliminated 2C9/2C19 inhibition and increased structural diversity. A new 6,5 heterobicyclic lead emerged, the imidazo $[1,5-a]$ pyridine G-868 ${ }^{20}$. G-868 went on to become a clinical candidate and was later renamed GDC-0623. ${ }^{19,21}$ The 6,5-imidazo $[1,5-a]$ pyridine scaffold was further optimized by incorporating a nitrogen at the 7 position to yield the 6,5 -heterobicyclic imidazo $[1,5-a]$ pyrazine core. The introduction of the $\mathrm{C} 7$ nitrogen was driven by increasing the structural diversity of the 6,5 heterobicycles while also adding polarity in a position where potency would be retained and metabolic stability improved. Even though in vivo met ID data did not lead us down this road, testing a hypothesis based on a MetaSite prediction resulted in the discovery of a fourth novel and potent 6,5 heterobicyclic scaffold, the imidazo [1,5- $a]$ pyrazines. The nitrogen at the 7 position did not result in an improvement in $\mathrm{hERG} I \mathrm{IC}_{50}$ as expected. The learning here was that lowering the lipophilicity (as reflected in lowering the LogD) is more important for improving hERG than pKa. The N7 modification did have an effect on physicochemical properties by reducing the plasma protein binding across species. The nitrogen increased metabolic stability and so lowered the unbound clearance. A nitrogen at C7 was not sufficient in itself to improve upon the oral exposure of G-868 (GDC-0623). Combining N7 with a diol hydroxamate which spread the polarity throughout the molecule gave imidazo [1,5- 
a]pyrazine G-479 which was improved over G-868 (GDC-0623) in many aspects (e.g., hERG , lower ppb across species, $14 x$ lower free drug $\mathrm{CL}$, improved(H/R/M) microsome stability and passive permeability, Table 4). The LLE analyses done retrospectively (Supplemental Material) demonstrates the progression of novel 6,5-heterobicycles towards increased LLE after moving away from the 5,6-aza-benzofuran scaffold.

The core change to the 6,5 heterobicyclic scaffold was potency driven and once discovered further diversified to give additional novel and potent 6,5 heterobicyclic MEKi's. G-479 did improve on G-868 (GDC-0623) in many aspects but due to the two fold potency loss in HCT116 cell proliferation assay coupled with the two fold lower oral exposure, G-479 was not able to displace G-868 (GDC-0623) as the development candidate.

This work is yet another example in the medicinal chemistry literature where small structural changes can have big consequences. The 6,5 heterobicycles were enabled by the crystal structure of the 5,6 aza-benzofuran G925. ${ }^{1 * *}$ Once the discovery of the first 6,5-heterobicyclic core was made, it offered an opportunity to utilize a successful medicinal chemistry strategy (especially for kinase inhibitors) of incorporating nitrogen atoms in specific places to add polarity, increase structural diversity, improve potency, PK, and properties and give rise to novel MEKi scaffolds. Use of the predictive tool MetaSite was rewarded by the discovery of imidazo [1,5-a]pyrazine G479. The design strategy taken was a successful one as demonstrated by the discovery of clinical candidate GDC0623 which has progressed to phase $1 b$.

\section{Acknowledgments}

The authors gratefully thank the purification and analytical groups within Genentech Small Molecule Drug Discovery for their support. We also thank Dr Joseph Lyssikatos for helpful discussions and encouragement in making the hydroxamate directly from the methyl ester as described in the patent literature, Dr. Mark Zak for his suggestion to try the trimethyl tin mediated hydrolysis of $\mathbf{9}$ after the more conventional hydrolysis procedure unexpectedly gave exclusively the decarboxylation product. Dr. Mark Zak and Dr. Anthony Estrada provided helpful discussions on the experimental details of the methyl ester hydrolysis. We acknowledge the use of synchrotron X-ray sources at APS (Advanced Photo Source-Argonne National Laboratory, outside Chicago IL) and SSRL (Stanford Synchotron Radiation Lightsource, Palo Alto CA)supported by the Department of Energy's (DOE) Office of Science. The SSRL Structural Molecular Biology Program is also supported by DOE's Office of Biological and Environmental Research, and by the National Institutes of Health (NIH). Refinement statistics for the structures in Figure 3 are summarized in the Supplementary Material.

\section{References and Notes}

1. Heald,R.A.; Jackson,P.; Savy, P.; Jones, M.; Gancia, E.; Burton, B.; Newman, R.; Boggs, J.; Chan, E.; Chan, J., Choo, E. Merchant, M.; Rudewicz, P.; Ultsch, M.; Weismann, C.;Yue, Q.;Belvin, M.; Price, S. J. Med. Chem. 2012, 55, 4594 ${ }^{* *}$ A reading of ref. 1 is recommended for key background information, the genesis of the 5,6 scaffolds and the origin and significance of isobenzothiazole G-155 which is used as the starting point for the G-479 discovery.

2. Downward, J. Nature Rev. Cancer 2003, 3, 11.

3. Bamford, S.; Dawson, E.; Forbes, S. ; Clements, J.; Pettett, R.; Dogan, A.; Flanagan, A.; Teague,J.; Futreal, P.A.;Stratton, M.R.; Wooster, R. Br. J. Cancer 2004, 91, 355. 
4. Hoshino, R.; Chantani, Y.; Yamori, T.; Tsuruo, T.; Oka, H.; Yoshida, O.; Shimada, Y.; Ari-I, S.; Wada, H.; Fujimoto, J.; Kohno, M. Oncogene 1999, 18, 813.

5. Hatzivassiliou, G.; Song, K.; Yen, I. Brandhuber, B.J.; Anderson, D.J.; Alvarado, R.; Ludlam, M.J.; Stokoe, D.; Gloor, S.L.; Vigers, G.; Morales, T.; Aliagas, I.; Liu, B.; Sideris, S.; Hoeflich, K.P.; Jaiswal, B.S.; Seshagiri, S.; Koeppen, H.; Belvin, M.; Friedman, L.S.; Malek S. Nature 2010, 464, 431.

6. Heidorn, S. J.; Milagre, C.; Whittaker, S.; Nourry,A.; Niculescu-Divas, I.; Dhomen, N.; Hussain,J.; Reis-Filo, J.S.; Springer, C.J.; Pritchard, C.; Marais, R. Cell 2010, 140, 209.

7. Poulikakos, P. I.; Zhang, C.; Bollag, G.; Shokat, K. M.; Rosen, N. Nature 2010, 464, 427.

8. Solit, D. B.; Garraway, L.A.; Pratilas, C.A.; Sawai, A.; Getz, G.; Basso, A.; Ye, Q.; . Lobo, J.M.; She, Y.; Osman, I.; Golub, T.R.; Sebolt-Leopold, J.; Sellers, W.R.; Rosen,N. Nature 2006, 439,358.

9. Wellbrock, C.; Karasarides, M.; Marais, R. Nature Rev. Mol. Cell Biol. 2004, 5, 875.

10. Flaherty, K.T; Infante, J.R.; Daud, A.; Gonzalez, R.; Kefford,R.F.; Sosman,J.; Hamid, O.; Schuchter, L.; Cebon,J.; Ibrahim, N.; Kaduchadkar, R.; Burris, H.A. III; Falchook, G.; Algazi, A.; Lewis, K.; Long, G.V.; Puzanov, I.; Lebowitz, P.; Singh, A.; Little. S.; Sung, P.; Allred, A.; Ouellet, D.; Kim, K.B.; Patel, K.; Weber, J. N. Engl. J. Med. 2012, 367,1694.

11. Clinical Trials.gov NCT01138085 Safety, PK of AKT and MEK Combination (GSK1120212 and GSK2141795) Currently recruiting patients.

12. Haagensen, E.J.; Kyle, S.; Beale, G.S.; Maxwell, R.J.; Newell, D.R. British Journal of Cancer 2012, 106, 1386.

13. Shimizu,T.; Tolcher, A.W.; Papadopoulos, K.P.; Beeram,M.; Rasco, D.W.; Smith, L.S.;Gunn, S.;Smetzer, L.; Mays, T.A.; Kaiser, B.; Wick, M.J.;Alvarez,C.;Cavazos, A.; Mangold, G.L.; Paitnaik, A. Clin. Cancer Res 2012, 18; 2316

14. Menzies, A.M.; Long, G.V. Ther Adv Med Oncol. 2013, 5,:278.

15. Wagle,N.;Van Allen, E.M. ;Treacy, D.J.; Frederick, D.T;Cooper, Z.A.;Taylor-Weiner, A.; Rosenberg, M.; Goetz, E.M.; Sullivan, R.J.; Farlow, D.N.; Friedrich, D.C; Anderka, K.;Perrin, D.; Johannessen, C.M.; McKenna, A.;Cibulskis, K.; Kryukov, G.; Hodis, E.;Lawrence, D.P.; Fisher, S.; Getz, G.; Gabriel, S.B.; Carter, S.L; Flaherty, K.T.; Wargo, J.A.; Garraway, L.A. Cancer Discov; 2014, 4, 61.

16. Price, S. Expert Opin. Ther. Pat. 2008, 18, 603.

17. Ohren, J. F.; Chen, H.; Pavlovsky, A.; Whitehead, C.; Zhang, E.; Kuffa, P.; Yan, C.; McConnell, P.; Spessard, C.;Banotai, C.; Mueller,W. T.; Delaney, A.; Omer, C.; Sebolt-Leopold, J. S.; Dudley, D. T.; Leung, I. K.; Flamme, C.; Warmus, J.; Kaufman, M.; Barrett, S.; Tecle,H.; Hasemann, C. A. Nature Struct. Mol. Biol. 2004, 11, 1192.

18. Fischmann, T. O.; Smith, C. K.; Mayhood, T. W.; Myers, J. E., Jr.; Reichert, P.; Mannarino, A.; Carr, D.; Zhu, H.; Wong, J.; Yang, R.; Le, H. V.; Madison, V. S. Biochemistry 2009, 48, 2661.

19. Hatzivassiliou,G.; Haling, J.R.; Chen,H.; Song,K.; Price,S.; Heald,R.; Hewitt,J.F.M.; Zak, M.; Peck, A.; Orr, C.; 
Merchant, M.; Hoeflich, K.P.; Chan,J.; Luoh, S-M.; Anderson, D.J.; Ludlam, M.J.C; Wiesmann,C.; Ultsch, M.;Friedman, L.S.; Malek, S., Belvin, M. Nature 2013, 501,232.

20. G-868 appeared in the patent literature in 2009: Price, S.; Heald, R.; Lee, W.; Zak, M. E.; Hewitt, J.; Frances M.; 2009 WO 85983 A1.

21. For the first public disclosure of the structure of GDC-0623, see Supplemental Material in reference 19.

22. G-606 appeared in the patent literature in 2009: Price, S.; Heald, R.; Savy, P.P.A.; 2009 WO 85980 A1.

23. Caron, G.; Ermondi G.; Testa, B. Pharm Res. 2007, 24, 480.

24. See also http://www.moldiscovery.com/publications.php MetaSite.

25. Jamieson, C.; Moir, E.M.; Rankovic, Z.; Wishart, G. J.Med Chem. 2006, 49, 5029.

26. Heald, R. A.; Jackson, P.; Lyssikatos, J.; Price, Stephen; Savy, P.P. WO2010/3025A1, 2010

27. All reactions except (e) were run in oven dried glassware cooled under $N_{2}$, under an atmosphere of $N_{2}$.

Reagents were used as received from commercial sources without any additional purification.

28. The preparation of 2-fluoro-4-(trimethylsilyl)aniline, was first disclosed in: Goutopolis,A.; Askew, B.C. Jr.; Chen, X.; Srinivasa, K.; Yu. H. 2007 W0123936 A1. See also Price, S.; Heald, R. Lee, W.; Zak, M.E.; Hewitt, J. Frances M.; 2009 WO 85983 A1; 2010 WO3025A1;2010 WO3022A1;2009 WO93013A1.

29. A fresh bottle of anhydrous DMF was degassed by sparging with nitrogen for $2 \mathrm{~h}$ prior to the running of the cyanation reaction.

30. Prior to adding the $10 \% \mathrm{Pd}-\mathrm{C}$ catalyst, the round bottomed flask was evacuated under house vacuum and filled with nitrogen $3 X$.

31. Reaction times longer than $1.5 \mathrm{~h}$ ( i.e., 3h) resulted in over-reduction products being formed.

32. Conc. $=0.16 \mathrm{M}$, and a suspension resulted . The reaction mixture to form (7) never became homogeneous.

33. After extractive workup (EtOAc., sat'd $\mathrm{NaHCO}_{3} /$ water/ brine wash, $\mathrm{Na}_{2} \mathrm{SO}_{4}$ drying), crude pdt. (7) was azeotroped with DCM to give an orange foam of suitable purity by LC/MS to be used directly without purification for the next step.

34. After extractive workup (EtOAc., sat'd $\mathrm{NaHCO}_{3} /$ water/ brine wash, $\mathrm{Na}_{2} \mathrm{SO}_{4}$ drying), crude pdt. (8) was azeotroped with DCM to give a yellow sold of suitable purity to be carried on directly to the next step.

35. Nicolaou, K.C.; Zak, M.; Safina, B.S.; Estrada, A.A.; Lee, S.H.; Nevalainen, M. J. Am. Chem. Soc. 2005, 127, 11176. 
36. After extractive workup (EtOAc., $1 \mathrm{M} \mathrm{HCl}(3 \mathrm{x})$ / water/ brine wash, $\mathrm{Na}_{2} \mathrm{SO}_{4}$ drying), the crude product (10) was treated with $\mathrm{DCM} / \mathrm{Et}_{2} \mathrm{O} /$ hexane. Crystals resulted which were collected by suction filtration and dried under house vacuum and used in the hydroxamate coupling reactions

37. Crude G-327 was purified by $\mathrm{SiO}_{2}$ chromatography (ISCO, $65-100 \% \mathrm{EA} /$ hex, followed by $0-50 \% \mathrm{MeOH} / \mathrm{EA}$.) and the resulting viscous oil treated with DCM ( 1 drop)/ ether/hexane to afford a yellow solid. The ether / hexane/ DCM solution from which the yellow solid precipitated was removed from the round bottomed flask via pipette, transferred to a second round bottomed flask and concentrated. The resulting oil was purified by prep HPLC to give additional G-327 of $>98 \%$ purity. The yellow solid that had precipitated after treatment with DCM (1 drop)/ ether/ hexane precipitate was dried under high vacuum overnight .

38. Crude hydroxamate was purified by $\mathrm{SiO}_{2}$ chromatography (ISCO, 0-10\% MeOH/DCM). G-573 and G-479 were crystallized from DCM/ ether/hexane. Collected yellow solid via filtration and dried under high vacuum overnight.

39. Marlow, A. L.; Wallace, E.; Seo, J.; Lyssikatos, J.P.; Yang, H. W.; Blake, J.; Storey, R. A.; Booth, R. J.; Pittam, J. D.;Leonard, J. et al 2007 WO044084 A2 20070419.

\section{Supplemental Material}

\section{IVIVc Plot Imidazo[1,5- $a$ ] pyridines}

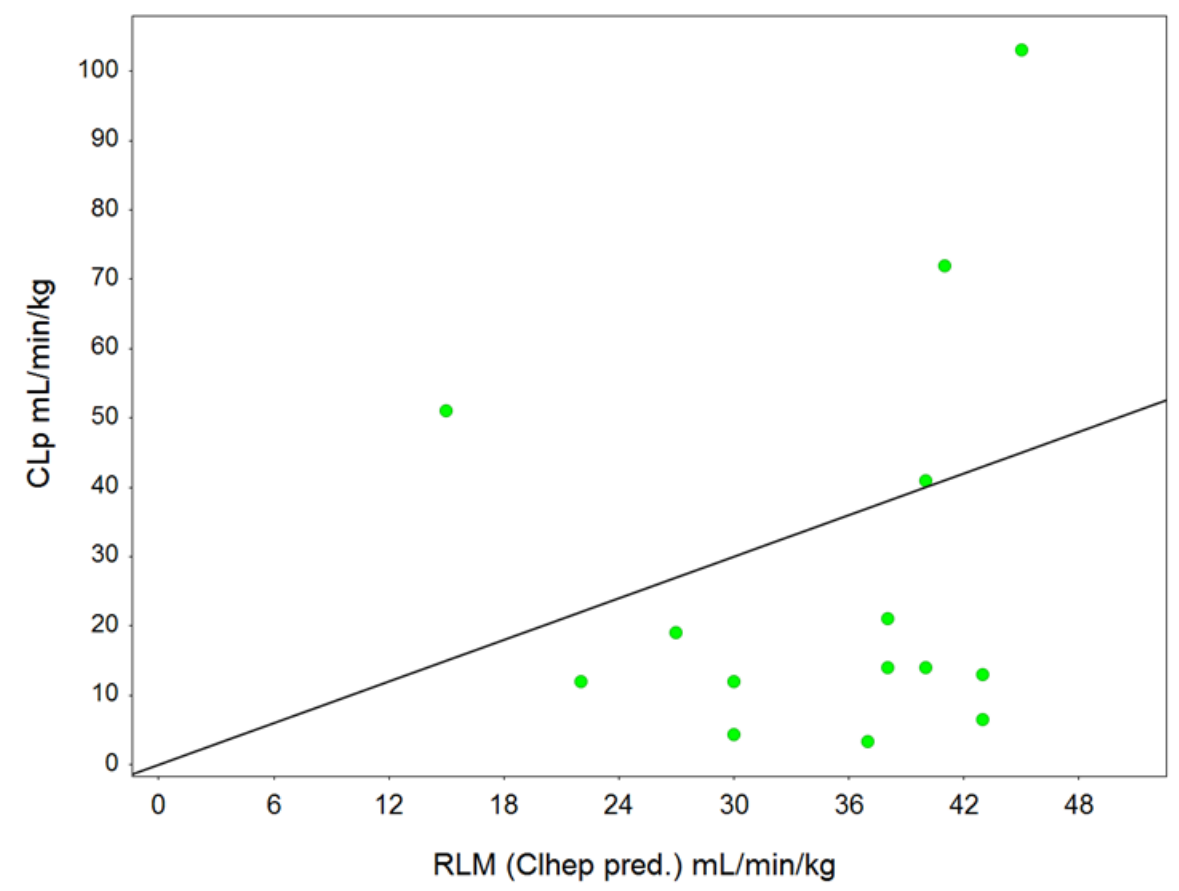

IV/IVc = in vitro/ in vivo clearance correlation (CL predicted from rat liver microsome incubation on $\mathrm{X}$-axis / versus total CL observed after intraveneous administration on the $\mathrm{Y}$-axis) for the imidazo[1,5- $a$ ] pyridines. 


\section{G-868 (MEK) In Vivo rat plasma}

Objective: To identify metabolites of G-868 in plasma from rats dosed PO (5mg/kg) study No 07-1276.

Method: Metabolite ID was done with the $5,15,30,60,1207240$ minute time points combined $\&$ extracted with acetonitrile. The supernatant was dried to a small volume to remove most of the acetonitrile.

Conclusion: Under the current experimental conditions seven metabolites were identified. Most of the metabolism takes place at the N-(2hydroxyethoxy)amide side chain with the free acid (M7) being the most significant metabolite.

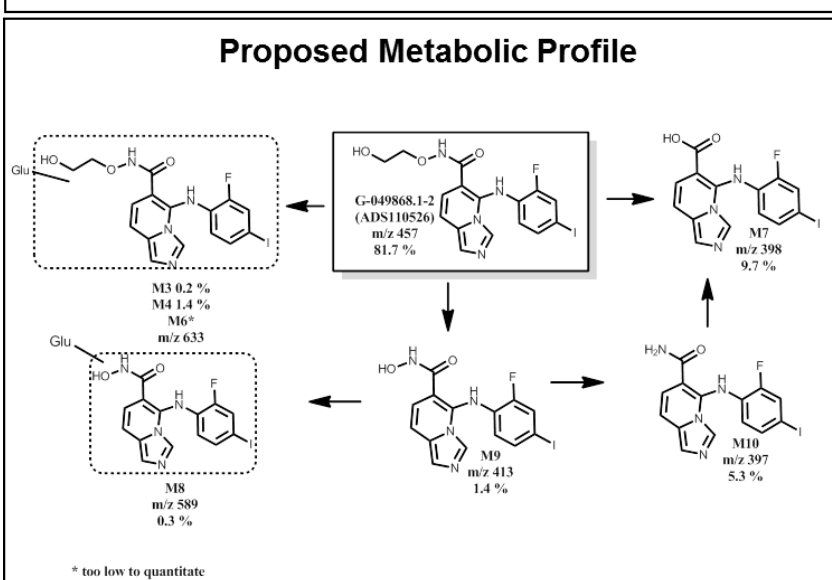

*Percent is normalized against the sum area counts

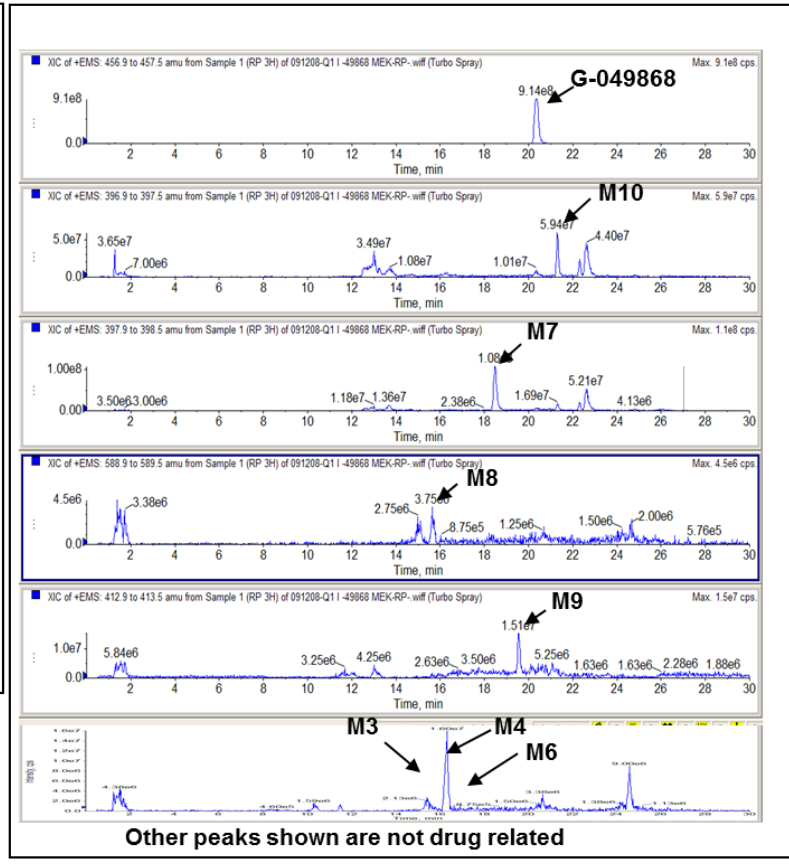


Lipophilic Ligand Efficiency (logD vs. pKi and cLogP vs. pKi for MEKi's)

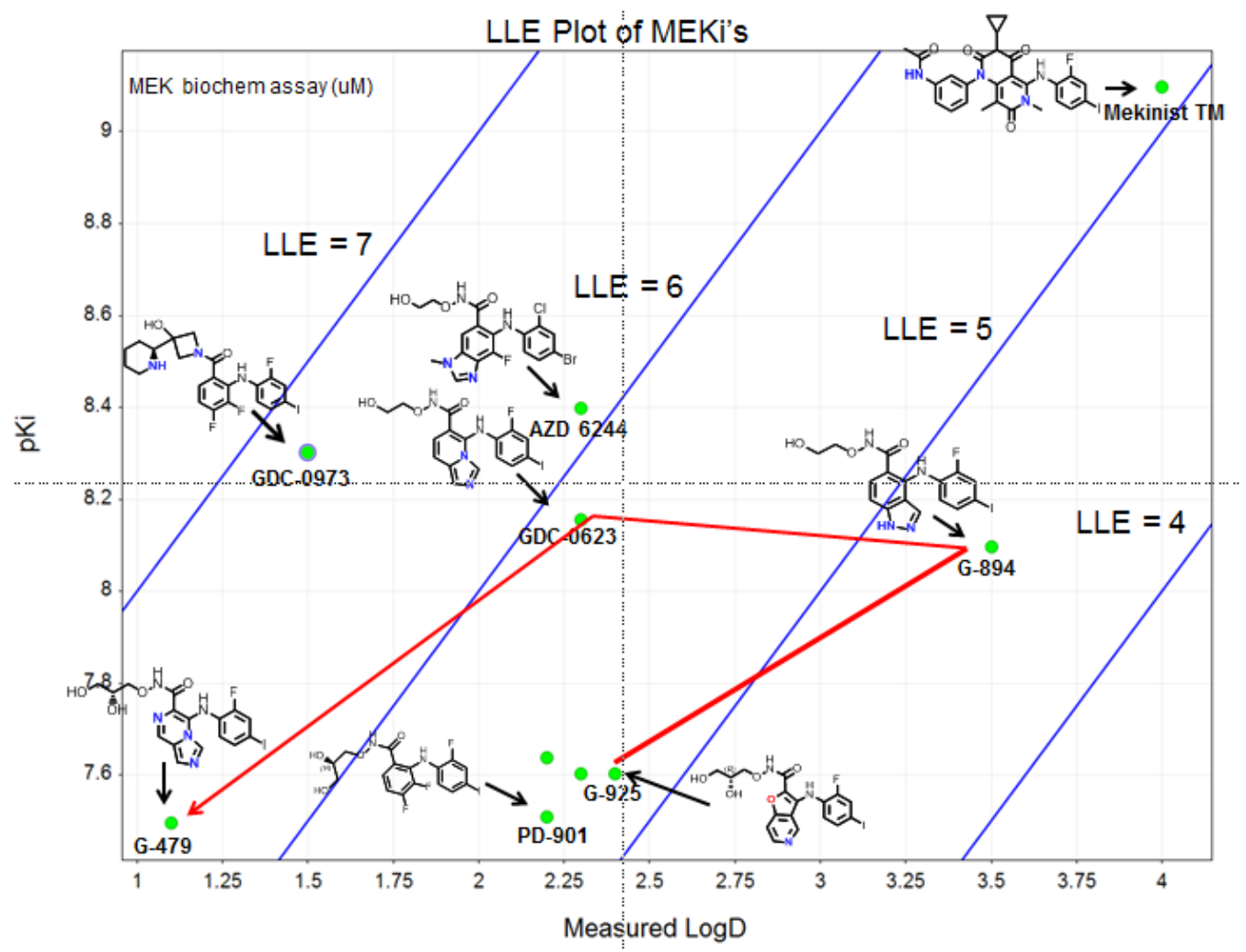

Retrospective LLE analysis .Biochemical potency versus measured LogD is plotted for the compounds described in this manuscript and reference compounds ( Mekinist ${ }^{\mathrm{TM}}$ the sole marketed MEKi, AZD6244, GDC-0973 two MEKi's in clinical studies and the PD-901 the first biaryl anilino scaffold disclosed which served as a starting point for many MEKi programs). It should be noted that the pKa of GDC-0973 is 8.5 which results in a lowering of the LogD. It is the combination of this lower LogD and high pKa that results in the high LLE rather than GDC-0973 having particularly great LLE. All of the other MEKi's included in this plot won't be ionized at neutral pH. 


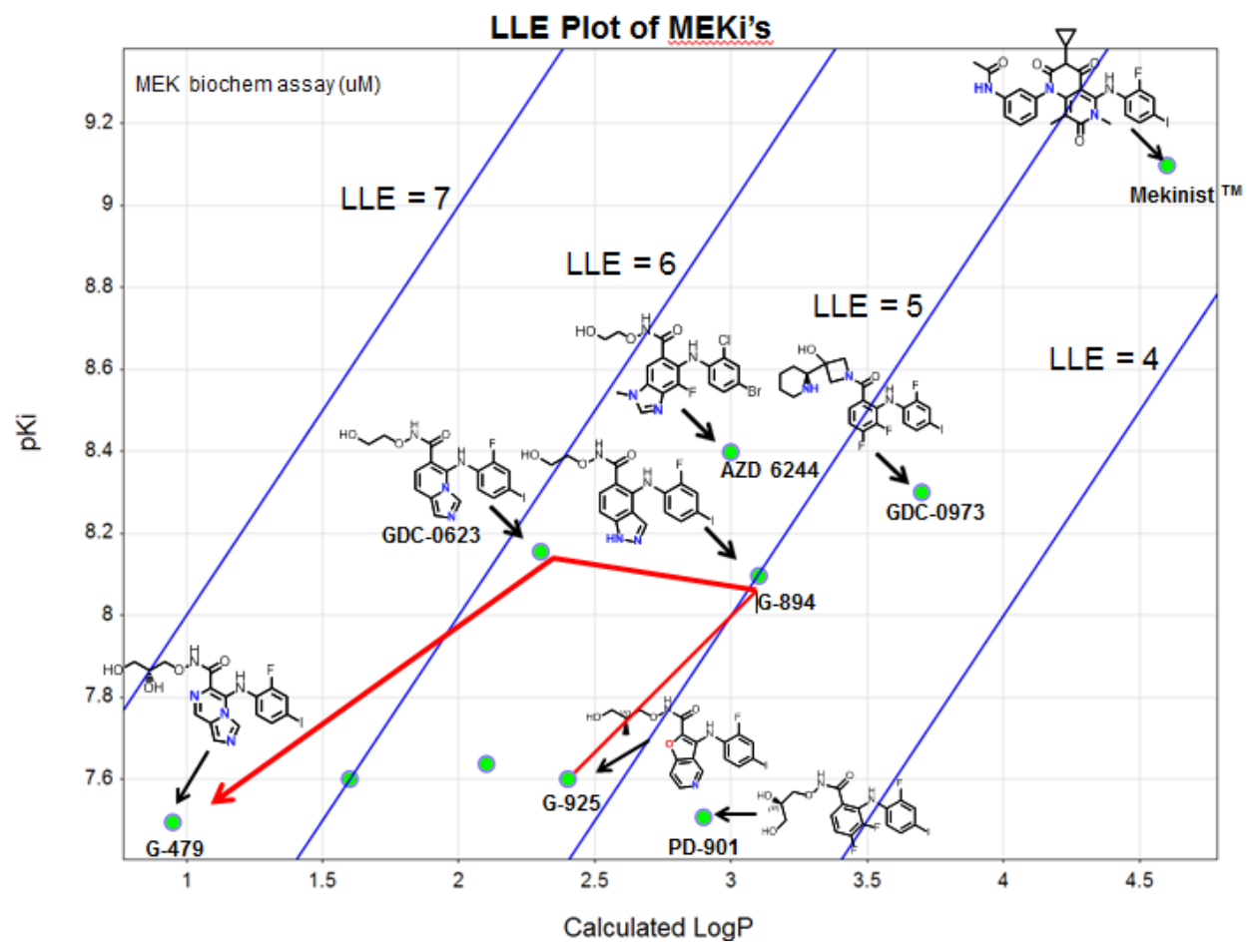

Retrospective LLE analysis.Biochemical potency versus measured CLogP (overall hydrophobicity) is plotted since measured $\log D$ takes into account charge and in doing so raises the possibly of overstating the LLE of charged compounds such as GDC-0973 which shifts 2.5 LLE units to the right when cLogP is utilized versus CLogD. The other MEKi's are neutral species at $\mathrm{pH} 7.4$ and as expected do not shift With the $\mathrm{x}$ axis $=$ cLogP, again there is a progression of the 6,5 bicyclic heterocyclic MEKi's towards towards greater LLE.

X-RAY TABLES

Table 1. Data Collection and Refinement for G-805 and G-799 Complexes MEK1/G-805

$\underline{\text { Data collection }}$

space group

unit cell $\left(\AA,{ }^{\circ}\right)$

$\mathrm{V}_{\mathrm{M}}\left(\AA^{3} /\right.$ Dalton $)$

Resolution $(\AA)$

Rsym ${ }^{\mathrm{a}, \mathrm{b}}$

Number of observations

Unique reflections

Completeness $(\%)^{\mathrm{b}}$

$\mathrm{I} / \sigma \mathrm{I}^{\mathrm{b}}$

Wilson B $\left(\AA^{2}\right)$

\section{Refinement}

Resolution $(\AA)$
SSRL 11-1

$\mathrm{P}_{2}$

$\boldsymbol{a}=81.845, \boldsymbol{b}=81.845$, $c=129.604$

3.29

$50-2.7(2.8-2.7)$

$0.08(0.588)$

20826

12041

99.9 (99.7)

17.9 (1.19)

76.3

$20-2.7$
MEK1/G -799

ALS 5.0.2

$\mathrm{P}_{2}$

$\boldsymbol{a}=81.899, \boldsymbol{b}=81.899$,

$c=129.24$

3.29

$50-2.8(2.9-2.8)$

0.068 (0.542)

61815

12111

$99.9(100)$

20.8 (2.75)

71.2

$20-2.8$ 
Number of reflections

12037

12105

$(\mathrm{F}>0 \sigma(\mathrm{F}))$

1.39

1.36

Final $\mathrm{R}^{\mathrm{c}}, \mathrm{R}_{\text {FREE }}$

$0.161,0.214$

$0.164,0.224$

Molecules/asymmetric unit 1

protein residues

291

1

286

water/ions/ligands

$11 / 1 / 2$

$13 / 1 / 2$

atoms

2349

2317

Mean B-factor $\left(\AA^{2}\right)^{\mathrm{d}}$

$70 / 60 / 70$

$67 / 58 / 67$

Rmsd bonds ( $\mathrm{A})$

0.009

0.009

Rmsd angles $\left({ }^{\circ}\right)$

1.25

1.38

Number of TLS groups 4

Ramachandran (\%)

$94.0 / 4.5 / 0.7 / 0.0$

3

$95.7 / 3.6 / 0.7 / 0.0$

${ }^{a}$ Rsym $=\Sigma|| \mathrm{I}|-|\langle\mathrm{I}\rangle|| / \Sigma|\langle\mathrm{I}\rangle|$, where $\mathrm{I}$ is the intensity of a single observation and $\langle\mathrm{I}\rangle$ the average intensity for symmetry equivalent observations.

${ }^{\mathrm{b}}$ In paren thesis, for the highest resolution shell.

${ }^{c} \mathrm{R}=\Sigma|\mathrm{Fo}-\mathrm{Fc}| / \Sigma|\mathrm{Fo}|$, where Fo and Fc are observed and calculated structure factor amplitudes, respectively. $\mathrm{R}_{\mathrm{FREE}}$ is calculated as $\mathrm{R}$ for reflections sequestered from refinement. ${ }^{\mathrm{d}}$ protein/ ligand/ all atoms

$\underline{\text { Table 2. Data Collection and Refinement for G-659 Complex }}$

\section{Data collection}

space group unit cell $\left(\AA,{ }^{\circ}\right)$

$\mathrm{V}_{\mathrm{M}}\left(\AA^{3} /\right.$ Dalton $)$

Resolution ( $(\AA)$

Rsym $^{\mathrm{a}, \mathrm{b}}$

Number of observations

Unique reflections

Completeness $(\%)^{\mathrm{b}}$

$\mathrm{I} / \sigma \mathrm{I}^{\mathrm{b}}$

Wilson B $\left(\AA^{2}\right)$
MEK1/G-659

ALS 5.0.1

$\mathrm{P}_{2}$

$\boldsymbol{a}=82.083, \boldsymbol{b}=82.083$,

$c=129.48$

3.29

$30-2.6(2.7-2.6)$

0.078 (0.752)

87074

13584

99.9 (100)

$30.2(2.25)$

56.95

$20-2.7$

13579

1.35

$0.167,0.218$

1

289

$35 / 1 / 2$

2359

$60 / 44 / 60$

0.008

1.17

4 
Ramachandran (\%) $\quad 95.7 / 3.5 / 0.7 / 0.0$

${ }^{a}$ Rsym $=\Sigma|| \mathrm{I}|-|\langle\mathrm{I}\rangle|| / \Sigma|\langle\mathrm{I}\rangle|$, where $\mathrm{I}$ is the intensity of a single observation and $\langle\mathrm{I}\rangle$ the average intensity for symmetry equivalent observations.

${ }^{\mathrm{b}}$ In parenthesis, for the highest resolution shell.

${ }^{\mathrm{c}} \mathrm{R}=\Sigma|\mathrm{Fo}-\mathrm{Fc}| / \Sigma|\mathrm{Fo}|$, where Fo and $\mathrm{Fc}$ are observed and calculated structure factor amplitudes, respectively. $R_{\mathrm{FREE}}$ is calculated as $\mathrm{R}$ for reflections sequestered from refinement. dprotein/ ligand/ all atoms

Use of the Stanford Synchrotron Radiation Lightsource, SLAC National Accelerator Laboratory, is supported by the U.S. Department of Energy, Office of Science, Office of Basic Energy Sciences under Contract No. DE-AC02-76SF00515.

The SSRL Structural Molecular Biology Program is supported by the DOE Office of Biological and Environmental Research, and by the National Institutes of Health, National Institute

of General Medical Sciences (including P41GM103393). The contents of this publication are solely the responsibility of the authors and do not necessarily represent the official views of NIGMS or NIH.

Use of the Advanced Photon Source was supported by the U. S. Department of Energy, Office of Science, Office of Basic Energy Sciences, under Contract No. DE-AC02-06CH11357. 
Table 1.

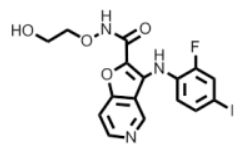

5,6 azabenzofuran

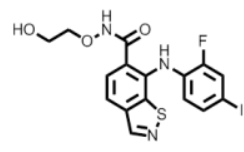

6,5 benzoisothiazole

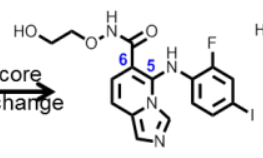

6,5 imidazo $[1,5-a]$ pyridines

\begin{tabular}{|c|c|c|c|c|}
\hline & G-963 & G-155 & $\begin{array}{c}\text { G-868 } \\
\text { 5-imidazopyridine }\end{array}$ & $\begin{array}{c}\text { G-606 } \\
\text { 8- imidazopyridine }\end{array}$ \\
\hline \multicolumn{5}{|l|}{ Cell Proliferation $\mathrm{EC}_{50}(\mu \mathrm{M})$} \\
\hline НСТ116 & 0.120 & 0.044 & 0.051 & 0.035 \\
\hline A3750 & 0.025 & 0.007 & 0.004 & 0.002 \\
\hline $\operatorname{clog} \mathrm{P}$ & 3.1 & 3.6 & 2.3 & 2.3 \\
\hline $\log D$ & 3.1 & 3.1 & 2.1 & 2.1 \\
\hline $2 \mathrm{C} 9 / 2 \mathrm{C} 19 \mathrm{IC}_{50}(\mu \mathrm{M})$ & $>10 />10$ & $1.3 / 1.8$ & $>10 />10$ & $7.3 / 16$ \\
\hline $3 A 4 t / m / 2 D 6 / 1 A 2 I C_{50}(\mu M)$ & $>10 />10 />10$ & $9.0 />10 />10$ & $>10 />10 />10$ & $>10 />10 />10$ \\
\hline
\end{tabular}

Increasing the polarity of the 6,5 heterobicyclic core lowers lipophilicity as reflected in measured LogD@ $\mathrm{pH}$ 7.4. 2C9/2C19 cytochrome $\mathrm{P} 450$ inhibition is decreased and cell proliferation potency maintained. Target $\mathrm{EC}_{50}$ for inhibition of cell proliferation was $\leq 0.050 \mu \mathrm{M}(\mathrm{HCT} 116)$ and $\leq 0.005 \mu \mathrm{M}$ (A375).

\section{Table 2.}

\begin{tabular}{|c|c|c|}
\hline Compound & $\begin{array}{c}\text { G-868 } \\
\text { 5-imidazo[1,5-a] pyridine }\end{array}$ & $\begin{array}{c}\text { G-606 } \\
\text { 8-imidazo[1,5-a] pyridine }\end{array}$ \\
\hline HCT116 prolif $\mathrm{IC}_{50}(\mathrm{uM})$ & 0.051 & 0.035 \\
\hline $\begin{array}{l}\mathrm{Mic}(\mathrm{H} / \mathrm{R} / \mathrm{M} / \mathrm{D} / \mathrm{C}) \text { pred.CLhep } \\
\mathrm{mL} / \mathrm{min} / \mathrm{kg}\end{array}$ & $\begin{array}{c}14 / 38 / 64 / 12 / 30 \\
\mathrm{M} / \mathrm{M} / \mathrm{H} / \mathrm{M} / \mathrm{M}\end{array}$ & $\begin{array}{c}15 / 40 / 75 / 23 / 38 \\
\mathrm{M} / \mathrm{M} / \mathrm{H} / \mathrm{H} / \mathrm{H}\end{array}$ \\
\hline $\begin{array}{l}\text { Rat PK } \\
\text { total } \mathrm{CL}(\mathrm{mL} / \mathrm{min} / \mathrm{kg}), \mathrm{T}_{1 / 2}(\mathrm{~h}) \text {, } \\
\mathrm{V}_{\mathrm{ss}}(\mathrm{L} / \mathrm{kg}), A \cup \mathrm{A}\left(\mu \mathrm{M}^{*} \mathrm{hr}\right) \% \mathrm{~F}\end{array}$ & $\begin{array}{c}13.2,1.7 \\
0.50,20,>100 \\
\end{array}$ & $\begin{array}{c}14.0,0.9 \\
0.46,6.0,37\end{array}$ \\
\hline hERG (patch clamp) $I C_{50}(\mu M)$ & 4.4 & 2.1 \\
\hline
\end{tabular}

Comparative potency, liver microsome stability $(\mathrm{H}=$ human, $\mathrm{R}=$ rat, $\mathrm{M}=$ mouse, $\mathrm{D}=\mathrm{dog}, \mathrm{C}=\mathrm{cyno}$,$) rat \mathrm{PK}$ and hERG patch clamp IC ${ }_{50}$ 's for G-868 (representative of the 5-imidazo [1,5- $a$ ] pyridine class of MEKi's) and G-606 (representative of the 8-imidazo[1,5-a] pyridine class of MEKi's). IV/PO dose=1/5 mpk. AUC for G-868 (IV/PO dose = 1/10 mpk) was normalized to a $5 \mathrm{mpk}$ dose. IV $/ \mathrm{PO}$ formulations = solution(60\% $\left.\mathrm{PEG} 400 / 40 \% \mathrm{H}_{2} \mathrm{O}\right) /$ solution $\left(60 \% \mathrm{PEG} 400 / 40 \% \mathrm{H}_{2} \mathrm{O}\right)$ for all compounds dosed. Dose volume $=$ $5 \mathrm{~mL} / \mathrm{kg}$ for all compounds dosed.

Liver microsomal stability ranges utilized for stable/moderate/labile designations; (CLhep) $\mathrm{mL} / \mathrm{min} / \mathrm{kg}$; Stable $(H / R / M)=<6.2 /<17 / 27$; Moderate $(H / R / M)=6.2-15 / 17-39 / 27-63 ;$ Labile $(H / R / M)=>15 />39 />63$. 
Table 3.

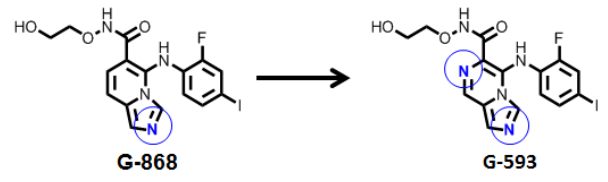

6,5 imidazo $[1,5-a]$ pyridine $\quad 6,5$ imidazo $[1,5-a]$ pyrazine

\begin{tabular}{|c|c|c|}
\hline HCT 116 cell prolif IC ${ }_{50}(u \mathrm{M})$ & 0.051 & 0.120 \\
\hline A375 cell prolif $\mathrm{IC}_{50}(\mathrm{uM})$ & 0.004 & 0.008 \\
\hline clogP/clogD & $2.3 / 2.3$ & $1.6 / 1.6$ \\
\hline $\begin{array}{c}\text { Predicted pKa (MOKA) } \\
\text { Predicted pKa (ACD) }\end{array}$ & 4.78 & 4.35 \\
Measured pKa (Sirius) & 5.84 & 3.34 \\
\hline LogD & 4.30 & 2.03 \\
\hline hERG patch clamp IC & 2.1 & 2.1 \\
\hline
\end{tabular}

Comparative cell proliferation potencies, cLogD/cLogP, LogD@ pH 7.4, calculated and measured pKa's and hERG patchclamp $\mathrm{IC}_{50}$ 's for imidazo [1,5-a] pyridine $\mathbf{G}-868$ and imidazo [1,5-a] pyrazine G-593 Illustrates the value of obtaining measured $\log D^{\prime}$ s on a routine basis (RSD for LogD $= \pm 0.30$ ). For the imidazo [1,5-a] pyrazine core, the logD may exert a bigger influence on the $h E R G I C_{50}$ than decreasing pKa.

Table 4.

\begin{tabular}{|c|c|c|c|c|c|c|c|c|}
\hline $\begin{array}{c}\mathrm{G \#} \\
\text { structure }\end{array}$ & $\begin{array}{c}\text { Cell prolif } \mathrm{IC}_{50}(\mu \mathrm{M}) \\
\text { HCT116/A375 }\end{array}$ & $\begin{array}{l}\text { clogP } \\
\log D\end{array}$ & $\begin{array}{c}\text { TS } \\
\text { pH 6.5, } \mu \mathrm{g} / \mathrm{mL})\end{array}$ & $\begin{array}{l}\text { Mic(H/R/M) } \\
(\mathrm{mL} / \mathrm{min} / \mathrm{kg})\end{array}$ & $\begin{array}{c}\mathrm{PK}(\mathrm{rat}) \mathrm{CL} / \mathrm{p} / \mathrm{CL} \text { (free) } \\
(\mathrm{mL} / \mathrm{min} / \mathrm{kg}) \\
\mathrm{F}(\%), \mathrm{AUC}(\boldsymbol{\mu M} * \mathrm{hr}) \\
\end{array}$ & $\begin{array}{c}\text { MDCK(A-B;B-A;B-A/A-B) } \\
10^{-6} \mathrm{~cm} / \mathrm{s}\end{array}$ & $\mathrm{ppb}(\mathrm{H} / \mathrm{R} / \mathrm{M})(\%)$ & $\begin{array}{c}\text { hERG patch clamp IC } \\
\text { ( } \mu \mathrm{M})\end{array}$ \\
\hline & $0.049 / 0.004$ & $\begin{array}{c}2.3 \\
2.05\end{array}$ & 41 (cryst) & $\begin{array}{c}14 / 38 / 64 \\
M / M / L\end{array}$ & $\begin{array}{c}13.2 / 1320 \\
100,20^{*}\end{array}$ & $6.20 / 16.5 / 2.6$ & $99.5 / 99 / 94$ & 4.4 \\
\hline & $0.035 / 0.002$ & $\begin{array}{c}2.3 \\
2.05\end{array}$ & 110 (amerph) & $\begin{array}{c}15 / 40 / 75 \\
\mathrm{M} / \mathrm{M} / \mathrm{L}\end{array}$ & $\begin{array}{c}14 / 636 \\
6,37\end{array}$ & $20.4 / 14 / 0.7$ & $98.5 / 97.8 / 95.1$ & 2.1 \\
\hline & $0.120 / 0.008$ & $\begin{array}{c}1.6 \\
2.10\end{array}$ & 150 (amorph) & $\begin{array}{c}11 / 41 / 54 \\
\mathrm{M} / \mathrm{L} / \mathrm{M}\end{array}$ & $\begin{array}{l}48 / 600 \\
38,1.48\end{array}$ & $19.7 / 14 / 0.7$ & $91 / 92 / 89$ & 3.3 \\
\hline & $0.052 / 0.005$ & $\begin{array}{l}2.1 \\
2.2\end{array}$ & 48 (amerph) & $\begin{array}{c}10 / 44 / 56 \\
\mathrm{M} / \mathrm{L} / \mathrm{M}\end{array}$ & $\begin{array}{l}44 / 800 \\
15,0.61\end{array}$ & ND & $90 / 94.5 / 91$ & 3.3 \\
\hline$\overline{\mathrm{G}-2}$ & $0.107 / 0.007$ & $\begin{array}{c}0.95 \\
1.1\end{array}$ & 12 (amorph) & $\begin{array}{c}8 / 19 / 29 \\
S / M / M\end{array}$ & $\begin{array}{l}12 / 92 \\
65,9.2\end{array}$ & $7.9 / 8.7 / 1.3$ & $86 / 87 / 87$ & 14 \\
\hline
\end{tabular}

Comparative potency, cLogP/LogD@ pH 7.4, thermodynamic solubility, liver microsome stability, rat PK, MDCK permeability and plasma protein binding ( $p p b$, human, rat, mouse ) for novel 6,5-heterobicyclic 
MEKi's G-868 and G-606 (imidazo [1,5- $a$ ] pyridine class), and G-593/G-327/G-479 (imidazo [1,5- $a$ ] pyrazine class). IV/PO dose $=1 / 5 \mathrm{mpk}$ and $1 / 10 \mathrm{mpk}$ G-868. ${ }^{*} \mathrm{AUC}$ normalized to a $5 \mathrm{mpk}$ dose for $\mathbf{G}-\mathbf{8 6 8}$. IV/PO formulations = solution $\left(60 \% \mathrm{PEG} 400 / 40 \% \mathrm{H}_{2} \mathrm{O}\right) /$ solution $\left(60 \% \mathrm{PEG} 400 / 40 \% \mathrm{H}_{2} \mathrm{O}\right)$ for all compounds dosed. Dose volume $=5 \mathrm{~mL} / \mathrm{kg}$ for all compounds dosed. 
Figure 1.

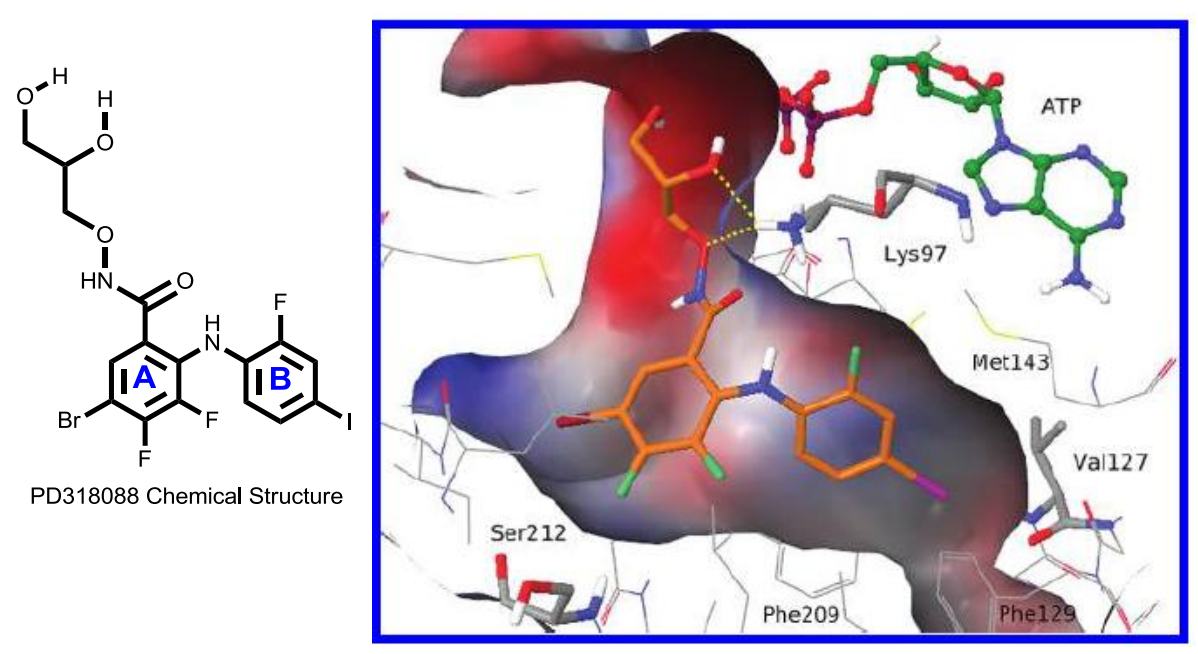

Figure 2.

年,

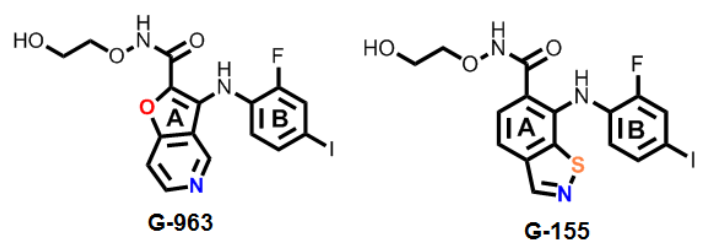

$$
\begin{array}{lrl}
\text { MEK1 HTRF } & \text { IC }_{50}=0.012 \mu \mathrm{M} & 0.012 \mu \mathrm{M} \\
\text { HCT 116 } & \text { cell prolif } \mathrm{EC}_{50}=0.120 \mu \mathrm{M} & 0.044 \mu \mathrm{M} \\
\text { A375 } & \text { cell prolif } \mathrm{EC}_{50}=0.025 \mu \mathrm{M} & 0.007 \mu \mathrm{M}
\end{array}
$$


Figure 3.

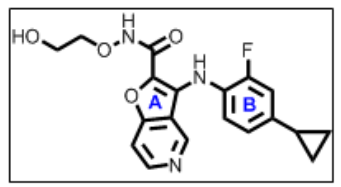

5,6 azabenzofuran

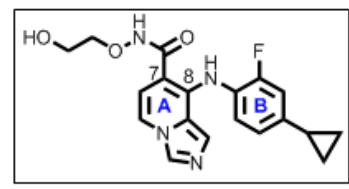

6,5 imidazopyridine

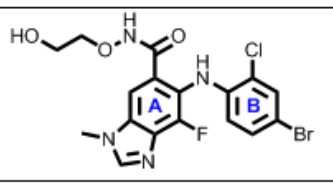

6,5 benzimidazole

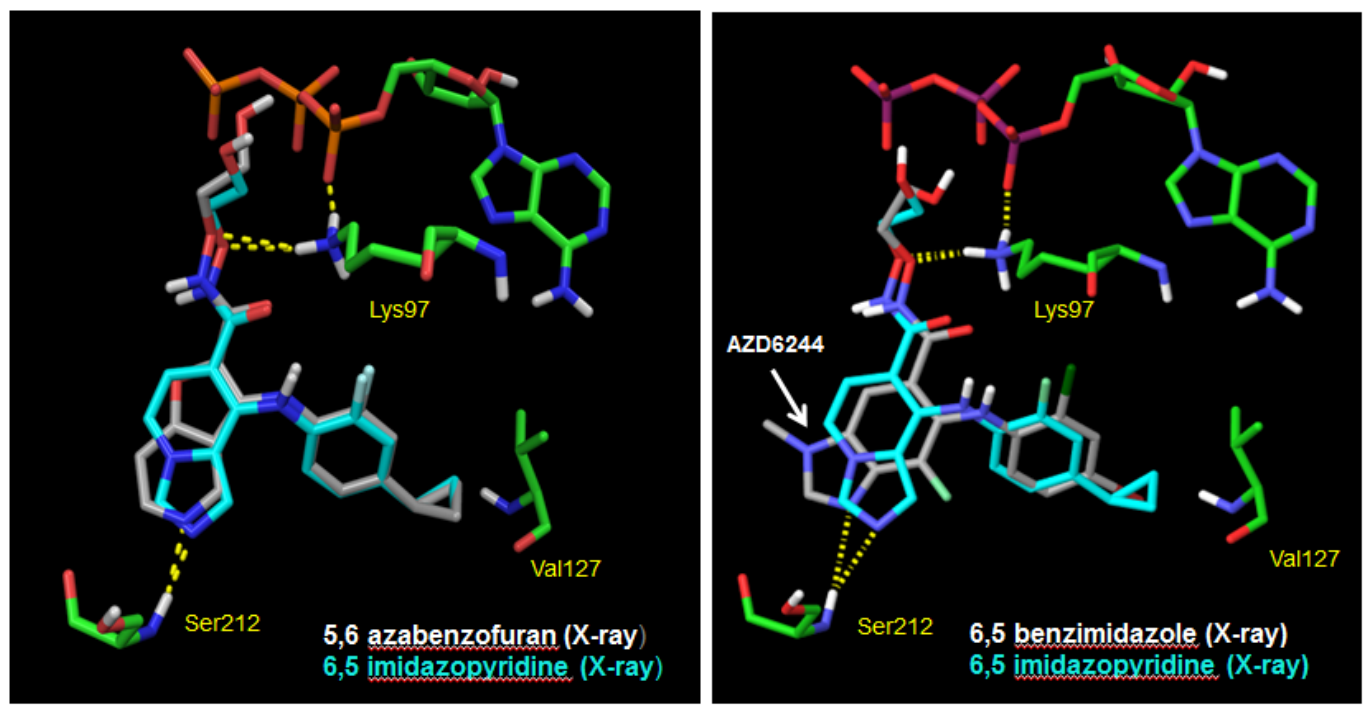

Figure 4.
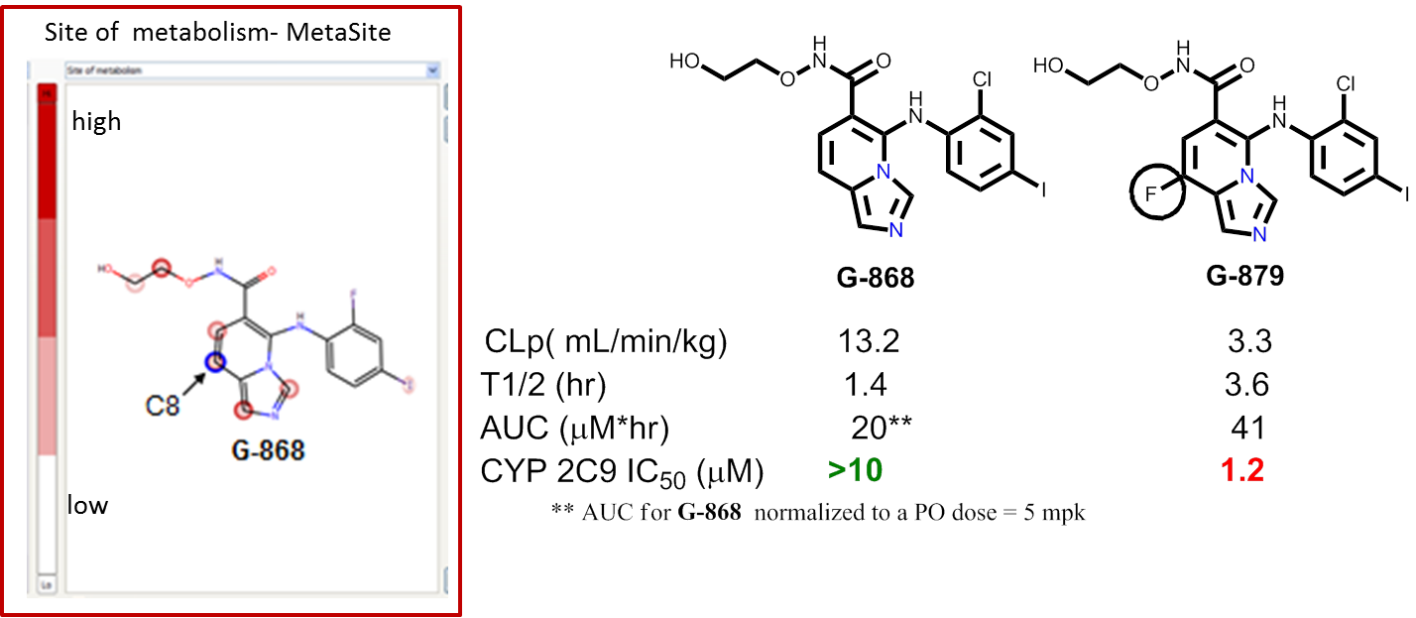

** AUC for G-868 normalized to a PO dose $=5 \mathrm{mpk}$ 
Figure 5.

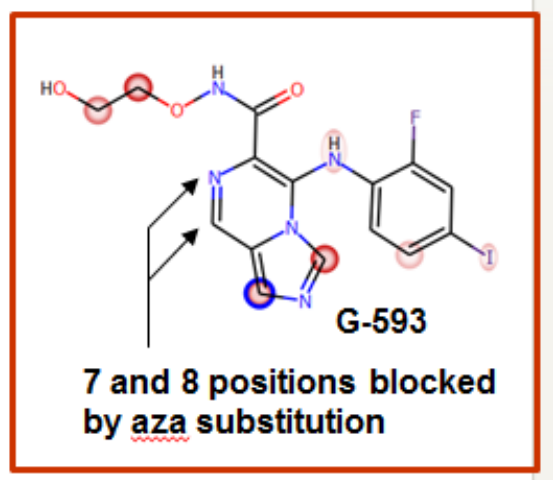

Figure 6.

Imidazo[1,5- $a$ ] Pyrazines
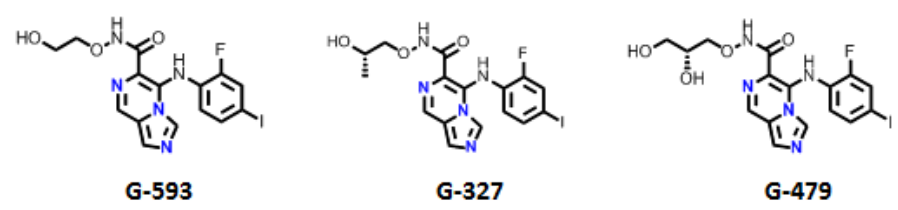
Fig 1. The key interactions of biaryl aniline MEK inhibitors: crystal structure of MEK1 in complex with ATP (green) and PD318088 (orange) (PDB code 1S9J). Figure 1 adapted with permission from Heald, R. A.; et al. J. Med Chem 2012, 55, 4594. Copyright 2012 American Chemical Society.

Fig.2 As predicted based on "fit" to the MEK pharmacophore model, 6,5 heterobicyclic isobenzothiazole G-155 exhibits increased cell proliferation potency versus its azabenzofuran comparator. HCT116 cell line was derived from malignant human colon cancer cells. A375 cell line was derived from malignant human melanoma cells.

Fig.3. Imidazo [1,5- $a$ ] pyridine binding mode. Left panel- co-crystal structure of a 5,6 azabenzofuran (2.8 Å resolution; PDB code 4U80) overlayed with a 6,5 imidazopyridine (2.7Å resolution; PDB code 4U81). The 6,5 imidazopyridine $\mathrm{N}$ is suitably placed for an $\mathrm{H}$-bond with Ser212 while maintaining the key hydroxamate and anilino pharmacophoric elements in a remarkably similar position as in G-925. Right panel- co-crystal structure of a 6,5 benzimidazole (AZD6244, 2.8 Å resolution; PDB code 4U7Z) overlayed with the same 6,5 imidazopyridine (PDB code 4U81). It is noteworthy that in the 6,5 imidazopyridine cocrystal structure the attachment point of the five membered ring heterocycle is shifted towards the Bring versus its attachment point in AZD6244. Despite the shift, the imidazopyridine nitrogen is positioned to make a robust $\mathrm{H}$-bond interaction to the Ser 212 while maintaining the key hydroxamate and anilino pharamcophoric elements in a remarkably similar position as in AZD6244. These X-ray cocrystal structures support the hypothesis from modelling that novel 6,5 heterobicycles would result in MEKi's that would fit well in the MEK binding pocket and have a high probability for equivalent or improved potency versus the 5,6 azabenzofuran core.

Fig. 4. C8 Fluorine substitution improved CLp, T1/2, and oral exposure( $P O$ dose $5 \mathrm{mpk}$, rat) but increased CYP2C9 inhibition activity sevenfold. The more intense the red circle, the higher probability of metabolism (color gradient shown on bar on right and indicates low probability to high probability of metabolism taking place on circled carbon). The major metabolic site is indicated by a blue circle. For $\mathbf{G}-$ 868, the MetaSite software identified C8 as the major metabolic site.

Fig. 5. Metasite analysis showing that a nitrogen incorporated at the $\mathrm{C} 7$ position removes two potential sites of metabolism. Note the major site of metabolism predicted by MetaSite is now the imidazo ring of the imidazo $[1,5-a]$ pyridine core.

Fig 6. Imidazo [1,5- $a]$ pyrazines G-593/G-327/G-479 


\section{Scheme 1.}
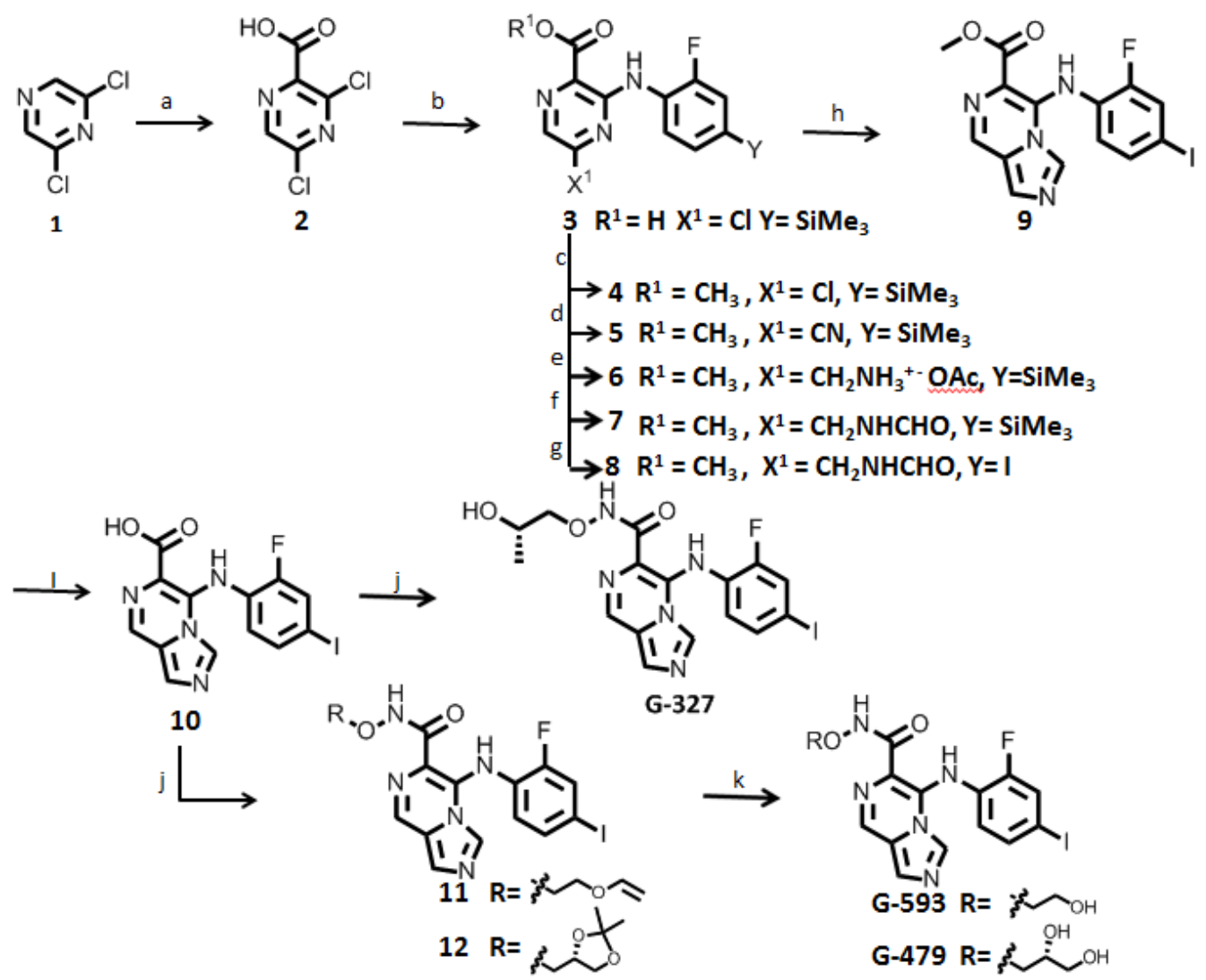

Reagents and conditions ${ }^{27}$ (a) (i) 1.02 eq freshly prep'd LDA, THF, 1.0 eq $1,-78^{\circ} \mathrm{C}, 2 \mathrm{~h}$ (ii) $\mathrm{CO}_{2}$ (xs), $41 \%$

yield.(b)(i)2.0 eq. ${ }^{28}$<smiles>C[PH](C)(C)c1ccc(N)c(F)c1</smiles>

$63 \%$ yield.(c)

$70 \%$ Toluene, $30 \% \mathrm{MeOH}(0.06 \mathrm{M}), 0^{\circ} \mathrm{C}, 2.3$ eq $\mathrm{TMSCHN}_{2}$ ( $2.0 \mathrm{M}$ in hexane), warm to $\mathrm{rt}, 1 \mathrm{~h}, 71 \%$ yield, crude pdt.4 used directly.(d) DMF ${ }^{29}, 1.0$ eq $4(0.16 \mathrm{M}), 1.1$ eq $\mathrm{Zn}(\mathrm{CN})_{2}, 0.125$ eq $\mathrm{Pd}\left(\mathrm{PPh}_{3}\right)$, microwave, 300 Watts, $150^{\circ} \mathrm{C}, 25 \mathrm{~min}, 78 \%$ yield.(e) 5 , glacial acetic acid $(0.15 \mathrm{M})^{30}, 10 \% \mathrm{Pd}-\mathrm{C}$ ( $20 \%$ by wt), $\mathrm{H}_{2}(1 \mathrm{~atm}$, balloon), $1.5 \mathrm{~h}^{31}, 98 \%$ yield, crude pdt 6 used directly.(f) $6,75 \%$ formic acid/25\% acetic anhydride ${ }^{32}$, rt $1.5 \mathrm{~h}^{33}, 80 \%$ yield, crude product 7 used directly $(\mathrm{g}) 7$, anhydrous $\operatorname{DCM}(0.1 \mathrm{M}), 0^{\circ} \mathrm{C}, 2.0$ eq iodine monochloride ( $1.0 \mathrm{M}$ sol' $\mathrm{n}$ in DCM) $, 0^{\circ}-\mathrm{rt}, 1 \mathrm{~h}^{34}, 98 \%$ yield, crude pdt.8 used directly.(h) 8, Toluene (0.025M, suspension), 4.2 eq $\mathrm{POCl}_{3}, 95^{\circ} \mathrm{C}, 1 \mathrm{~h}, \mathrm{SiO}_{2}$ purified (ISCO $35-100 \% \mathrm{EA} /$ hex, followed by $0-30 \%$ $\mathrm{MeOH} / \mathrm{EA}) 46 \%$ yield.(i) 9,anhydr. 1,2 DCE (0.14M), 3.5 eq $\mathrm{Sn}\left(\mathrm{CH}_{3}\right)_{3} \mathrm{OH}, 85^{\circ} \mathrm{C}, 1 \mathrm{~h}, 98 \%$ yield ${ }^{35},{ }^{36}(\mathrm{j}) \mathbf{1 0}$,

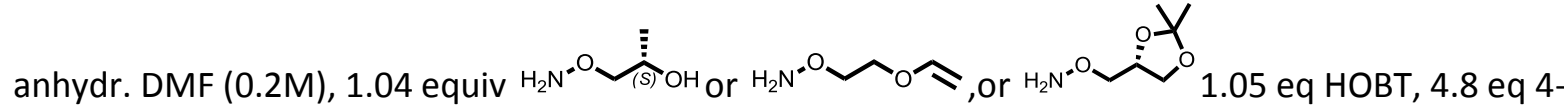
methylmorpholine, 1.05 eq EDCl, rt, $17 \mathrm{~h}$ to $3 \mathrm{~d}, 50 \%$ yield $\mathbf{G}-\mathbf{3 2} \mathbf{7}^{37}$, (k) anhydrous DCM/ MeOH (2:1), 1.5eq $4 \mathrm{M} \mathrm{HCL}$ in 1,4 dioxane, rt, $1 \mathrm{~h}$ (ii) 6.0 eq solid $\mathrm{NaHCO}_{3}, \mathrm{rt}, 15 \mathrm{~min}$, then $\mathrm{Na}_{2} \mathrm{SO}_{4}$ filter and purify on $\mathrm{SiO}_{2}(\mathrm{ISCO}, 0-15 \% \mathrm{MeOH} / \mathrm{DCM}), 48 \%$, 32\% over coupling / deprotection steps G-593/G-479) ${ }^{38}$ 
Scheme 2.
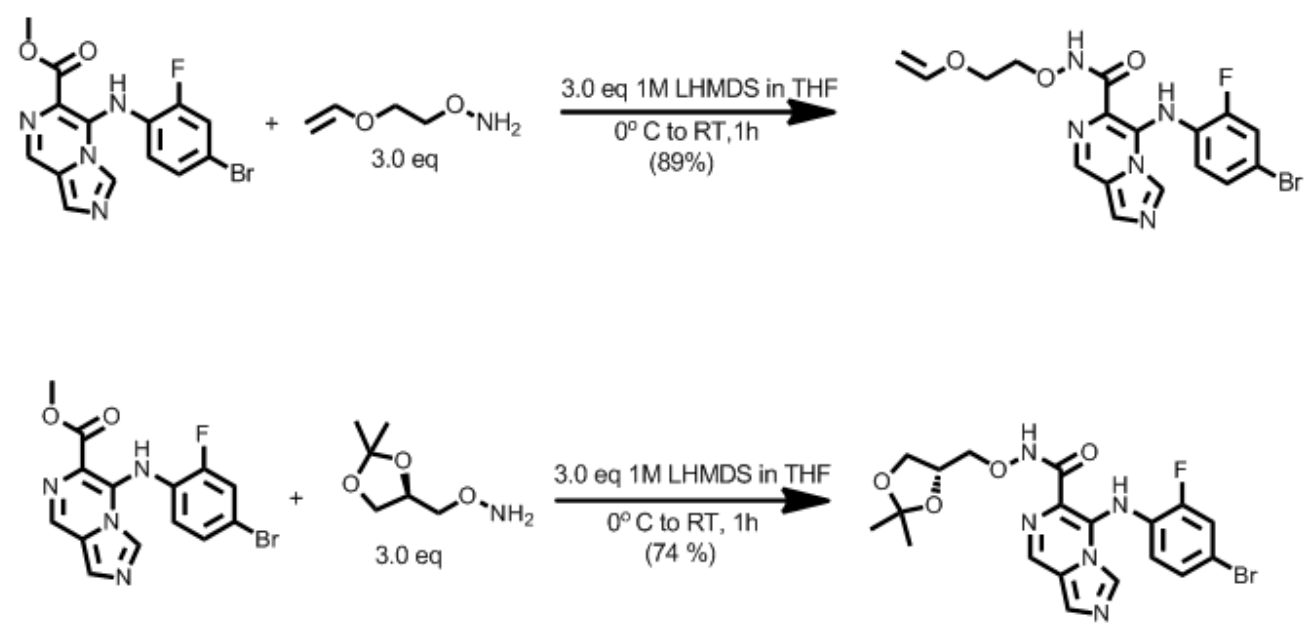

Preparation of hydroxamate directly from the methyl ester 


\section{Graphical Abstract}

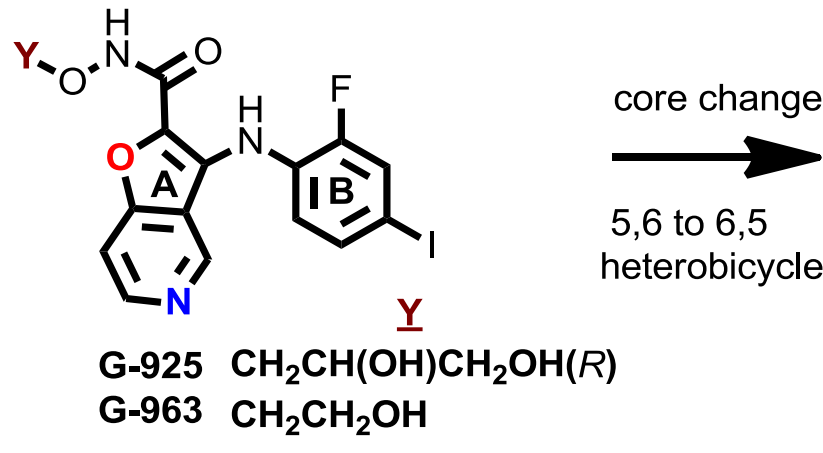

aza-benzofuran MEKi's

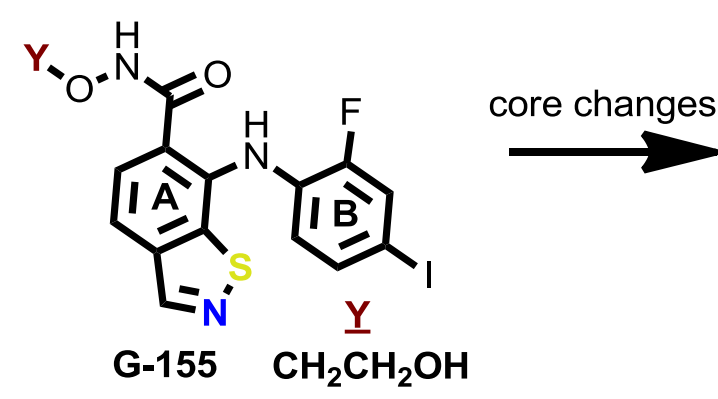

benzoisothiazole MEKi

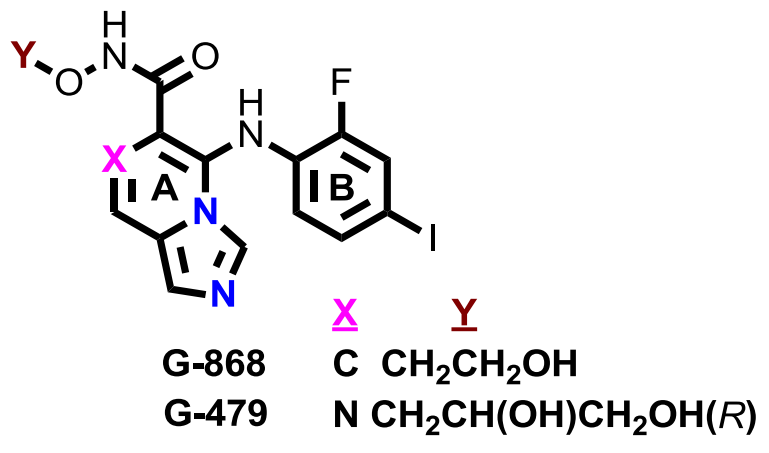

imidazo [1,5-a] pyridine MEKi imidazo [1,5-a] pyrazine MEKi 